
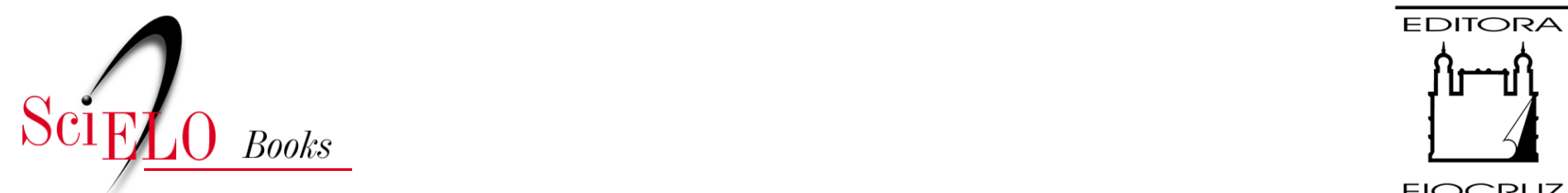

FIOCRUZ

\title{
Clássicos \& Comentários 3-Gaspar Vianna - Contribuição para o estudo da anatomia patológica da 'moléstia de Carlos Chagas' (esquizotripanose humana de tireoidite parasitária)
}

\author{
José da Rocha Carvalheiro \\ Nara Azevedo \\ Tania C. de Araújo-Jorge \\ Joseli Lannes-Vieira \\ Maria de Nazaré Correia Soeiro \\ Lisabel Klein \\ (orgs.)
}

\section{SciELO Books / SciELO Livros / SciELO Libros}

CARVAlHEIRO, J. R., AZEVEDO, N., ARAÚJO-JORGE, T. C., LANNES-VIEIRA, J., SOEIRO, M. N. C., and KLEIN, L., eds. Gaspar Vianna - Contribuição para o estudo da anatomia patológica da 'moléstia de Carlos Chagas' (esquizotripanose humana de tireoidite parasitária). In: Clássicos em Doença de Chagas: histórias e perspectivas no centenário da descoberta [online]. Rio de Janeiro: Editora FIOCRUZ, 2009, pp. 149-178. ISBN: 978-65-5708-101-3.

https://doi.org/10.7476/9786557081013.0008.

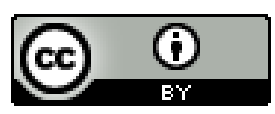

All the contents of this work, except where otherwise noted, is licensed under a Creative Commons Attribution $\underline{4.0 \text { International license. }}$

Todo o conteúdo deste trabalho, exceto quando houver ressalva, é publicado sob a licença Creative Commons Atribição 4.0.

Todo el contenido de esta obra, excepto donde se indique lo contrario, está bajo licencia de la licencia $\underline{\text { Creative }}$ Commons Reconocimento 4.0. 


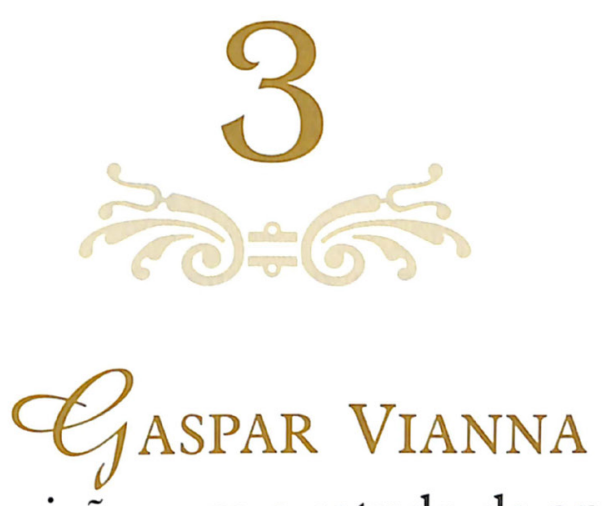

Contribuição para o estudo da anatomia patológica da 'moléstia de Carlos Chagas'

(esquizotripanose humana de tireoidite parasitária). Memórias do Instituto Oswaldo Cruz, 3: 276-293, 1911. 


\section{Gaspar Vianna (1885-1914)}

Médico paraense do Instituto de Manguinhos, desenvolveu importantes estudos histopatológicos sobre a doença de Chagas, dos quais destaca-se a descoberta de que o Trypanosoma cruzi multiplica-se no interior dos tecidos e não no sangue, como observado em outros tripanossomos. 


\title{
Contribuição para o estudo da anatomia patolojica da "Molestia de Carlos Chagas"
}

\author{
(Esquizotripanoze humana ou tireoidite parazitaria) \\ PELO \\ Dr. Gaipar Viamian.
}

\section{Beitrag zum Studium der Pathologischen Anatomie der Krankheit von Carlos Chagas}

(Schizotrypanose des Menschen oder parasitaere Thyreoiditis)

VON

Dr. Gasipax Tiarana.

A convite do Dr. Carlos Chagas, encetámos o estudo das alterações histolojicas na esquizotripanoze pela pesquiza no sistema nervozo. Infetámos varios gatos e o material nos pareceu desde logo magnifico para o estudo das lezões do sistema nervozo, porque os exemplares inoculados aprezentaram fenomenos curiozos de perturbações motoras, principalmente notaveis nos membros, sendo os poste:iores por mais vezes e com mais intensidade acometidos.

Aos primeiros passos no assunto, tivemos de suspender o trabalho para acudir ao estudo do material d'uma autopsia, em individuo morto pela molestia. Realizada no cadaver d'uma criança de 3 mezes, com o diagnostico de esquizotripanoze de forma aguda, feito em vida pelo proprio Dr. Chagas, atinjiam as peças colhidas um grande valor.
Auf Ansuchen von Dr. Carlos ChaGAS begann ich das Studium der histologischen Veränderungen bei der Schizotrypanose mit der Untersuchung des Nervensystems. Ich infizierte verschiedene Katzen und das Material schien mir von vorn herein für das Studium der Läsionen des Nervensystems äusserst günstig, weil die geimpften Tiere merkwürdige Erscheinungen motorischer Störungen boten, welche besonders an den Extremitäten bemerkbar waren, wobei die hinteren häufiger und intensiver befallen wurden.

Nach kaum begonnenen Studien musste ich diese Arbeit unterbrechen, um mich der Untersuchung des Sektionsmateriales zuzuwenden, welches von einem an der Krankheit Verstorbenen herriihrte. $\mathrm{Da}$ es sich um ein dreimonatliches $\mathrm{K}$ ind handelte, bei welchem während des Lebens von Dr. Carlos Chagas die Diagnose einer akuten Form der Schizotrypanose gestellt worden war, kam dem gewonnenen Material eine besondere Bedeutung zu. 
Efetivamente revelaram os córtes lezões curiozissimas que apenas esquematicamente podem ser referidas no momento atual.

Apoz esta, novas necropsias fez o Dr. Chagas, de modo que até hoje atinjem a ro o numero de cazos de que temos as viceras para estudo histopatolojico.

Segundo informações do Dr. Chagas sobre as lezões macroscopicas encontradas nas autopsias realizadas, parece possivel julgar por ellas, com baze firme, se o cadaver pertence a um esquizotripanozico. Apezar da amolestia de Carlos Chagas aprezentar varias modalidades clinicas, existe, na faze letal, quer se trate de cazo agudo, quer de cazo cronico, um conjunto de lezões capaz de por si só, deixar prezumir a especificidade das modificações morbidas. O quadro patolojico varia de intensidade de uma a outra forma, mas não se modifica qualitativamente.

Aos sinais constantes observados sempre por CHAGAS, outros se juntam conforme a séde da principal lezão observada em vida.

Assim num cadaver da forma cardiaca é intuitivo que o coração seja o ponto de lezões intensas e carateristicas.

Nas formas nas quais ha lezões cronicas do sistema nervozo, a meninjite ou melhor, a encefalo-meninjite, associa o seu quadro de lezões particulares aos sinais gerais e constantes.

Das palavras, pronunciadas pelo $\mathrm{Dr}$. Chagas na sua conferencia na Academia Nacional de Medicina e de apontamentos, que nos ministrou pessoalmente, deduzimos este quadro geral para as necropsias da molestia : a Poliorominite generalizada. $O$ liquido existente nas serozas é citrino. Existencia constante de numerozos gan-
In der Tat ergaben die Schnitte äusserst merkwürdige Veränderungen, über welche ich gegenwärtig nur in schematischer Weise berichten kann.

Nach dieser machte Dr. Chagas noch weitere Sektionen, so dass heute die Zahl der Fälle, von denen innere Organe fiir die histologische Untersuchung vorliegen, bereits zehn beträgt.

Nach den Mitteilungen von Dr. ChAGAS über die makroskopischen Veränderungen, welche bei den ausgeführten Sektionen beobachtet wurden, erscheint es möglich, nach denselben mit Sicherheit zu beurteilen, ob eine Schizotrypanuminfektion vorliegt. Obgleich die Krankheit von Carlos Chagas verschiedene klinische Formen zeigt, so besteht doch, wenn sie zum Tode führt, sowohl bei akuten, wie bei chronischen Fällen, ein Symptomenkomplex, der für sich allein gestattet, die Spezifizität der krankhaften Veränderungen vorauszusetzen. Das pathologische Bild der verschiedenen Formen zeigt eine ungleiche Intensität, ohne sich qualitativ zu ändern.

$\mathrm{Zu}$ den von Chagas beständig beobachteten Anzeichen kommen, entsprechend dem hauptsächlichen Sitze der während des Lebens beobachteten Krankheitserscheirungen, andere hinzu.

Demgemäss wird, falls im Leben die Herzsymptome vorgeherrscht haben, in der Leiche das Herz besonders intensive und charakteristische Erscheinungen darbieten.

Bei den Formen, die längere Zeit nervöse Störungen zeigten, fügt die Meningitis oder richtiger Encephalomeningitis die die ihr eigentümlischen Veränderungen $\mathrm{zu}$ den allgemeinen und charakteristischen Erscheinungen hinzu.

Aus den Mitteilungen, welche Dr. Chagas bei Gelegenheit seines Vortrages in der Academia Nacional de Medicina machte und aus den Notizen, die er mir persönlich gab, konstruiere ich für die Sektionen bei dieser Krankheit das folgende Bild :

Allgemeine Polyorrhomenitis mit serösem Ergusse von gelber Farbe. - Kon- 
glios aumentados de volume na cavidade abdominal, mediastino, pescoço, axilas e virilhas. Dejeneração gorduroza do figado. mais ou menos acentuada conforme a morbidez do cazo, sendo nas formas agudas comparavel á dejeneração identica observada na febre amarela. Baço lijeiramente aumentado de volume e, por vezes, friavel. Existencia infalivel de lezões tireoidianas escleroticas, hipertroficas e produzindo verdadeiros cistos, ás vezes com zonas calcificadas. Não raro, verificam-se miocarditt e lezões das capsulas suprarenais ».

Fóra deste quadro geral, ficam, é claro, lezões outras localizadas em pontos diversos do organismo.

Este nosso trabalho abranjerá um conjunto de fatos histo-patolojicos já estabele cidos nos cazos humanos, com verificações em animais de laboratorio.

Descreveremos, em primeiro lugar, as alterações cardiacas e musculares, passando depois ás assinaladas no sistema nervozo, e por fim ás que são de séde glandular.

Entretanto só o faremos rezumidamente, rezervando a ampliação deste estudo para publicações posteriores, que enquadraremos em 7 capitulos, distribuidos nesta ordem: I. $^{\circ}$ - aparelho circulatorio e sistema muscular; $2 .^{\circ} \rightarrow$ glandulas de secrȩ̧ões internas; $3 .^{\circ}$ - sistema nervoso $; 4^{\circ}$ - aparelho respiratorio $5 .^{\circ}$ - aparelho genito-urinario; $.6^{\circ}$ - aparelho dijestivo e glandulas anexas; $7 .^{\circ}-$ ossos, cartilajens, tecido conjuntivo e pele.

\section{ALTERAÇÕES CARDIACAS}

O coração $€$ uma das viceras de predileção do esquizotripano, quer no homem, quer nos animais.

Verificam-se lezões em todos os tecidos constitutivos do orgam, variando de intensidade e de aspeto conforme se trate de cazo agudo, cardiaco ou cronico. stante Schwellung zahlreicher Lymphdrüsen der Bauchhöhle, des Mediastinums, des Halses, der Achselhöhlen und Inguines. Je nach der Intensität der Krankheit,mehr oder weniger ausgesprochene, fettige Degeneration der Leber, die in den akuten Formen der bei Gelbfieber beobachteten gleichkömmt. - Leicht geschwollene und manchmal erweichte Milz. - Ganz konstantes Vorkommen von Schilddrüsenveränderungen in Form von Sklerose, Hypertrophie und wirklicher Zystenbildung, manchmal mit Verkalkungszonen. - Häufiges Bestehen von Myocarditis und Nebennierenveränderungen.

Ausser diesem Allgemeinbilde giebt es natürlich noch Veränderungen, die sich in verschiedenen Körperregionen lokalisieren.

Diese Arbeit soll einen Komplex histopathologischer Befunde umfassen, welche beim Menschen erhoben und bei Laboratoriumstieren kontrolliert wurden. Ich beschreibe in erster Linie die Herz- und Muskelveränderungen, wende mich dann zu denjenigen des Nervensystems und befasse mich schliesslich mit solchen der drüsigen Organe.

Es soll dies aber nur in aller Kürze geschehen, indem ich die Ausarbeitung des Themas auf spätere Publikationem verspare; dieselben sollen sieben Kapitel in folgender Anordnung umfassen: I. Kreislaufsorgane und Muskelsystem. 2. Drüsen mit innerer Sekretion. 3. Nervensystem. 4. Atmungsorgane. 5. Urogenitalorgane. 6. Verdauungsapparat und zugehörige Drüsen. 7. Hämatopoietische Organe. 8. Knochen, Knorpel, Bindegewebe und Haut.

\section{VERAENDERUNGEN AM HERZEN.}

Das Herz gehört zu den Organen, in welchen sich das Schizotrypanum vorzugsweise lokalisiert; man findet verschiedene Veränderungen in allen seinen Geweben, die in ihrer Intensität und in ihrem Aussehen wechseln, je nachdem die $K$ rankheit akut, chronisch oder hauptsầchlich durch Herzsymptome charakterisiert war. 
Para clareza da expozição, descreveremos primeiramente as lezões das celulas nobres, depois as do tecido de sustentaculo, serozas e vazos.

Nos cazos nos quais o orgam é portador dos germens, encontram-se dentro dos segmentos de Weissmann espalhados por toda a espessura do musculo cardiaco, parazitos de forma arredondada, com um nucleo e blefaroplasto.

Estas formas do parazito variam muito numericamente no interior da celula cardiaca, vendo-se delles em divizão binaria. Celulas ha que possuem numero reduzido de protozoarios, em contraste com outras pejadas de centenas delles.

Nas celulas de numero muito diminuto de germens, estes localizam-se na parte ceatral, perto do nucleo, isto é, no protoplasma não diferenciado.

Por multiplicação tomam a zona do sarcoplasma, atinjem á parte fibrilar que destroem localmente.

E' facil verificar em córtes transversas das fibras, excavações produzidas pelos escuizotripanos na parte contratil por elles ocupada.

Com a multiplicação sempre crecente do hospede, o processo destrutivo extendese pelo maior eixo da celula, atinje os segmentos de WeIssmanN que com ella se unem, formando-se deste modo um cisto parazitario de grande volume.

A fibra assim lezada não aprezenta grande alteração em sua fibrilação, pois as estriaçc̃es lonjitudinal e transversal continuám perfeitamente observaveis com os metodos ordinarios de coloração.

$\mathrm{Ha}$, é certo, celulas nas quais o parazito, cauzu, quazi por completo, o dezaparecimento da parte diferenciada, reduzindo-as á membrana.

Verifica-se por vezes a multiplicação do nucleo e, raro, lijeira pigmentação no protoplasma.
Bchufs grösserer Verständlichkeit werde ich zuerst die Veränderungen der spezifischen Organzellen beschreiben und nachher die des Stützgewebes, der Serosa und der Gefässe.

In den Fällen, in welchen das Herz Parasiten beherbergt, finden sich in den Weissmann'schen Segmenten iiber die ganze Dicke des Herzmuskels zerstreute Parasiten von runder Form mit Kern und Blepharoplast. Die Zahl dieser in den Herzmuskelzellen liegenden Parasitenformen schwankt sehr; viele derselben erscheinen in binärer Teilung hegriffen. Während manche Zellen nur eine geringe Zahl von Protozoen aufweisen, zeigen sich dagegen andere von Hunderten derselben erfiillt.

Enthalten die Zellen nur eine sehr geringe Anzahl von Parasiten, so lokalisieren sich dieselben in den zentralen Teilen, in der Nähe des Kernes, d. h. im nicht differenzierten Teile des Protoplasma. Bei ihrer Vermehrung befallen sie die ganze Sarkoplasmazone und erreichen den fibrillären Anteil, welchen sie langsam zerstören. Auf Querschnitten der Fasern bemerkt man leicht Hohlräume, welche durch die Schizotrypanumformen in der von ihnen bewohnten kontraktilen Zone hinterlassen wurden.

Bei beständig weiterschreitender Vermehrung der Schmarotzer breitet sich der Zerstörungsprozess in der I.ängsaxe der Zelle aus und erreicht die WeissmanN'schen Segmente, welche mit ihm verschmelzen und eine voluminöse Zyste parasitärer Natur bilden.

Die befallene Faser weist in ihrer Struktur keine grosse Veränderung auf, indem sich Längs- und Querstreifung bei den gewöhnlichen Färbemethoden erkennen lassen. Es giebt freilich Zellen, bei denen der Parasit den differenzierten Teil fast völlig zum Schwinden bringt, indem bloss eine Membran übrig bleibt.

Man beobachtet manchmal eine Vermehrung des Kernes und nicht selten eine leichte Pigmentierung im Protoplasma. 
Muitas aprezentam ruturas de suas membranas, em determinados pontos onde, parece-nos, foi mais ativo o processo destruidor.

Quando se dá este fato, não raro, existem, perto do ponto onde se deu a rutura, esquizotripanos flajelados.

Estas formas do parazito pórlem ser observadas no interior das fibras. principalmente naquellas que tem grandes reuniões parazitarias.

Cumpre referir ainda que existem cazos nos quais ha dejeneração bastant $€$ curioza da celula cardiaca, sem, comtudo, serem vistos aí parazitos, ao passo que a infeção é pozitivamente verificada em outras celulas do organismo.

No tecido conjuntivo disposto de permeio ás fibras, observam-se ora fenomenos inflamatorios generalizados (cazo agudo), ora fócos esparsos em varios pontos.

Nas inflamações encontram-se, muitas vezes, parazitos fagocitados ou não.

Os fenomenos inflamatorios são muitas vezes localizados ao redor de fibras parazitadas, mas não só, ha zonas infiltradas sem haver parazitos, como ha muitas celulas parazitadas sem reação pericelular.

Sempre que se dá rutura de uma fibra cardiaca, produz-se reação franca por parte do tecido conjuntivo e elementos outros afluem para este ponto, certamente em defeza do orgam.

Aí é comum verem-se esquizotripanos fagocitados e outros já sobıe fibras não parazitadas.

Além destes pontos reacionarios existem inflamações perivasculares, algumas bastante pronunciadas, outras apenas esboçadas.

Entretanto ha vazos que conservam a integridade morfolojica de suas paredes.

Nos cazos agudos verificámos fenomenos de pericardite e endocardite, mas debalde pesquizámos o parazito nestas lezões.

Num cazo da forma cardiaca os fenomenos de pericardite eram muito pronun-
Bei vielen Zellen zerreisst die Membran an bestimmten Stellen, wo, anscheinend, der Zerstörungsprozess besonders intensiv war. In diesem Falle finden sich nicht selten in der Nähe des Risses geisseltragende Schizotrypanumformen Man kann dies auch im Innern der Fasern beohachten, besonders solcher, welche grosse Parasitenansammlungen enthalten.

Es verdient auch, erwähnt zu werden, dass zuweilen eine ziemlich merkwïrdige Degeneration der Herzmuskelzelle vorkömmt, ohne dass man daselbst Parasiten wahrnähme, während in anderen Zellen desselben Organismus die Infektion deutlich erkennbar ist.

An dem, zwischen den Muskelfasern gelegenen, Bindegewebe bemerkt man bald ausgebreitete Entziindungserscheinungen (iu akuten Fällen), bald an verschiedenen Stellen zerstreute Herde. Bei den Ertzündungen findet man häufig Parasiten, bald in Phagozyten, bald frei.

Die entzündlichen Erscheinungen treten häufig in der Umgebung parasitenhaltige' Fasern auf, indessen giebt es nicht nur ent zündete Zonen ohne Parasiten, sonden auch von solchen befallene Zellen ohe perizelluläre Reaktion.

Reisst eine Herzmuskelfaser ein, so erfolgt immer eine deutliche Reaktion on Seite des Bindegewebes und es samreln sich andere Elemente an diesem Purkte, unzweifelhaft zum Schutze des Orgnes. Hier sieht man dann häufig phagocyierte Schizotrypana und andere, bereits auf parasitenfreien Fasern gelegene.

Ausser diesen Reaktionspunkte" giebt es noch, zum Teil sehr deutliche, zu Teile kaum angedeutete, perivaskuläre intzündungen. Es giebt aber auch jefässe, deren Wände eine morphologiscie Integrität aufweisen.

In akuten Fällen beobarstete ich Erscheinungen von Peri- und E, locarditis, suchte aber vergebens nach Jurasiten in diesen Läsionen.

In einem Falle mit Herzerscheinungen waren die Zeichen vo Pericarditis besonders deutlich, indem sich auch 
ciados, havendo mesmo pontos hemorrajicos; a miocardite e a lezão cardio-celular igualmente nitidas.

Até agora não nos foi possivel encontrar alterações nos grandes vazos cardiacos que temos estudado.

\section{MUSCULOS ESTRIADOS.}

$\mathrm{Na}$ esquizotripanoze o musculo é ponto dos mais prediletos para a multiplicação do parazito. Verificámos a sua infestação na cobaia, um mez apoz a inoculação; e, em seguida, nos musculos humanos.

Pensamos atualmente que o musculo e o coração formam a pedra de toque para o diagnostico histo-patolojico da molestia de Chagas. O tecido muscular, poucos dias apoz a inoculação de sangue parazitado na cobaia, já se acha lezado pelo tripanozomo.

Suas alterações são muito curiozas, quer pelo modo de se comportar da celula, quer pelas reações do endomizio.

Os musculos do homem e animais esquizotripanozicos nem tojos se acham atacados pelo elemento invazor, porém muites delles aprezentam lezões em grande percurso. Em cobaias infetadas verifiquei, algumas vezes, os musculos da perna e o psoas abranjidos em todo o seu comprimento.

Em cazos humanos constatei a infeção em grandes extensões dos musculos da perna, dorso, braço, etc.

A celula muscular estriada, como a celula cardiaca, póde ter em seu interior, numero variavel de parazitos: umas, onde se inicia o processo, mostram raros exemplares; outras, ao contrario, deixam vêr milhares de individuos.

Geralmente estes grandes acumulos de parazitos tomam a forma de fuzo, na parte central da fibra, sem deformar-lhe o contorno. A integridade da estriação é per- punktförmige Hämorrhagien vorfanden; die interstitielle Myocarditis und die Läsionen der Herzmuskelzellen waren gleichfalls deutlich.

Bis jetzt war es mir nicht möglich, an den von mir studierten grossen Herzgefässen Veränderungen zu entdecken.

\section{ALLGEMEINE WILLKUERLICHE MUSKULATUR.}

Bei der Schizotrypanose ist die Muskulatur ein Ort der Wahl für die Vermehrung des Parasiten. Ich beobachtete deren Infektion beim Meerschweinchen einen Monat nach der Einimpfung und später in den menschlichen Muskeln.

Ich glaube zur Zeit, dass das Herz und die willkürlichen Muskeln bei der histo-pathologischen Diagnose der Krankheit von Chagas den Prïfstein bilden. Das Muskelgewebe des Meerschweinchens zeigt, bereits wenige Tage nach der Einspritzung des parasitenhaltigen Blutes, von Trypanosomen herrihrende Läsionen.

Zwei Veränderungen sind besonders merkwürdig, sowohl wegen des Verhaltens der Zelle selbst, als wegen der Reaktion von Seiten des Endomysiums.

Bei der Schizotrypanose des Menschen und der 'Tiere werden nicht alle Muskeln von der Invasion befallen, aber viele derselben zeigen Läsionen in weiter Ausdehnung. Bei infizierten Meerschweinchen beobachtete ich einige Male, dass Psoas und Beinmuskulatur in ihrer ganzen Länge ergriffen waren. Beim Menschen fand ich eine sehr ausgedehnte Infektion der Bein-, Arm- und Riickenmuskulatur.

Wie die Herzmuskelzelle, kann auch diejenige der Körpermuskeln in jhrem Innern eine wechselnde Zahl von Parasiten aufweisen; solche, bei denen der Prozess im Beginn ist, zeigen nur wenige Exemplare, andere dagegen Tausende von Individuen.

Gewöhnlich nehmen grosse Parasitenanhäufungen im zentralen Teile der Faser eine Spindelform an, ohne deren Umriss zu stören. Die gute Erhaltung der Strei- 
feitamente patente. mesmo perto dos pontos destruidos (Fstampa r f. Fig. 1)

Em nada, na maioria das fibras, é alterada a coloraçio pelos metodos habi. hituais de investigaçōes histolojicas.

Nos cazos nos quais o parazito se dis punha na periferia da subtancia estriada, logro abaixo do sareolemit, retansente no sarcoplasma. verilicata-se a destruiçás da parte diferenciarla e a reproduça do para. zito.

Vimos algumas fibras cuja fibrilaçio havia dezaparerielo. ficanto em seu lugar substancia hialina.

Estas lihras parazitadas nan aprezen tam. em algums cazos, alteração alguma reveladora da reação celular contra o elemento invazor. nem o endomizio se modifica 'm sua vizinhança ; outras, porém, deixam vêr que a proliferação nuclear é um fato, e mais que a ração inflamatoria se estabelece intensamente nas circumvizinhanças do ponto afetado.

Chegado a certo ponto de plenitude, isto é, quando não mais o sarcolema póde ronter os esquizotripanos dezenvolvidos no seu interior, dá-se a rutura em alguns pontos do elemento anatomico, e parazitos, uns ainda redondos, outros já flajelados, são lançados nos intersticios das fibras musculares.

Em córtes transversais esta evolução póde ser seguida a passo, e as figuras $2-4$ da estampa $\mathbf{I} 4$ reprezentam as suas principais fazes. Muitas rezes não se vê no ponto mais dilatado do fuzo de parazitos fibrilas musculares, estando aí a celula reduzida a pequena camada de protoplasma e membrana.

Dada a rutura do elemento muscular. os parazitos, como já dissemos, vão ter ao endomizio onde são vistos izolados, incluidos em celulas de defeza e juxtapostos a outras fibras.

Fstas fibras aprezentam-se umas infetadas por algumas unidades parazitarias, e outras integras, parecendo que as infetadas fung ist selbst in der Nahe ter Zerstörungsherle vollstänlig klar. (Tafel I f. Fig. I).

Bei Anwendung der gelvänhlichen Farbemethoden keigt sich hei fer Mehrzahl ler Fasern die Fäbung durehans nirht verändert.

In den Fallen, wo tie Parasiten in der Peripherie der restreiften Substanz dicht unter dem sarcolemm und sicher im Sareoplasma lasen, heobachtete ich eine Zerstörung des differenzicrten Anteiles und cinc Reproduktion des Parasiten.

Ich sah einige Fasern, bei denen die Faserung wershwundell und eine hyaline Sulstan\% an deren Stelle getreten war.

In manchen fallen zeiren solche infizierte Fasern keine Veränderung. welche wine keaktion der Zelle gegen das invadierencle Element beweist, noch wird das Endomysium in ihrer Nachbarschaft modiliziert ; andere dagegen zeigen das tatsächliche Vorkommen einer Kernvermehrung und iiberdies das Auftreten einer intensiven entziindlichen Reaktion in der L'mgebung des hefallenen Punktes.

Nach einer kurzen Periode der Anfüllung, wenn das Sarcolemm die in seinem Innern sich entwickelnden Parasiten nicht mehr aufnehmen kann, erfolgt die Ruptur cler Zelle an einigen Punkten und die teils runden, teils bereits geisseltragenden Parasiten ergiessen sich in die Interstitien der Muskelfasern.

Auf Querschnitten kann dieser Vorgang Schritt für Schritt verfolgt werden und Taf. I 4, Fig. 2-4 zeigt seine hauptsächlichsten Phasen. Oft sieht man am breitesten Teile der Parasitenspindel keine Fibrillen mehr, da die Zelle hier auf die Membran und eine dünne Protoplasmaschicht reduziert ist.

Wie gesagt, gelangen dic Parasiten nach erfolgter Ruptur des Muskelelementes ins Endomysium, wo sie, einzeln in zur Abwehr dienenden Zellen eingeschlossen und anderen Fasern angelagert, angetroffen werden. Diese Fasern erscheinen bald unversehrt, bald mit einigen Parasiten infiziert, wobei die letzteren anschei- 
são as que com mais facilidade deixaram o parazito atravessar a membrana.

A multiplicação nuclear, apoz a saida de parazitos, ativa-se; a fibra é invadida por celulas migradoras; os nucleos das celulas, envolvidos por camada protoplasmica, misturam-se com os elementos para aí aportados. No ponto no qual a fibra foi destruida, não raro apoz o que acabamos de referir, vêm-se como se fossem tubos cheios de elementos reacionarios, os restos do sarcolema.

Para o lado do tecido conjuntivo dos musculos infetados, é facil, mesmo com aumento fraco, verificar zonas de infiltração mais ou menos extensas, constituidas por celulas frequentemente mononucleares.

Os vazos que irrigam os musculos infetados, principalmente os de pequeno calibre, sofrem infiltração celular de suas paredes, sobretudo da externa.

\section{SISTEMA NERVOZO.}

Nesta parte o nosso estudo abranjerá somente lezões do sistema nervozo central e principalmente observadas na forma aguda da molestia.

Quanto ao sistema nervozo periferico, as nossas observações até agora feitas não nos autorizam a estabelecer de modo absoluto as lezões patolojicas nelle encontradas.

Num cazo agudo, bastante parazitado, verificámos, mesmo com fraco poder ampliador, e em córtes de qualquer parte do tecido nervozo, córados por qualquer processo, modificações morbidas muito pronunciadas do tecido nobre, bem como, em menor intensidade, lezões vasculares e meninjeanas.

No cerebro, cerebelo, nucleos da baze, protuberancia, bulbo, medula em varios segmentos, viam-se fócos inflamatorios espalhados em toda a substancia nervoza, quer branca, quer parda, e destacaveis ao mais superficial exame microscopico.

Variando muito de tamanho, sem distribuição regular, esses fócos, em sua nend eine für den Parasiten leichter durchgängige Membran besitzen.

Nach dem Austritte der Parasiten wird die Kernvermehrung eine lebhaftere; Wanderzellen dringen in die Muskelfaser ein und die von einer Plasmaschicht umgebenen Kerne vermischen sich mit den eingedrungenen Elementen, so dass nicht selten später, an Stelle der zerstörten Faser, die Reste des Sarcolemms als ein mit Entziindungsprodukten erfüllter Schlauch erscheinen.

Am Bindegewebe der infizierten Muskel kann man, bereits mit schwacher Vergrösserung, mehr oder weniger ausgedehnte Entzündungsherde konstatieren, welche von - häufig einkernigen - - Zellen gebildet sind.

Die Gefässe, welche die infizierten Muskel bedienen und zwar besonders die feineren, zeigen eine zellige Infiltration der Wandschichten, namentlich der äussersten.

\section{NERVENSYSTEM.}

Hier befassen sich meine Studien nur mit den Veränderungen am zentralen Nervensystem und zwar besonders denjenigen der akuten Erkrankungen. Die Bs obachtungen, welche ich am peripheristsien Nervensystem angestellt habe, gestatten mir nicht, in absoluter Weise, daselbst vorkommende pathologische Zustände aufzustellen.

In einem akuten. an Parasiten ziemlich reichen Falle konstatierte ich, schon mit schwacher Vergrösserung und in beliebig gefärbten Schnitten irgend eines Teiles des Zentralnervensystems, sehr ausgedehnte krankhafte Veränderungen des spezifischen funktionellen Gewebes und auch, obwohl in geringerem Masse, Veränderungen an Gefässen und Meningen.

Im Gross- und Kleinhirn, in den Nervenkernen der Basis, Brücke und Medulla oblongata und in verschiedenen Rückenmarksabschnitten sah man in der ganzen Nervensubstanz, der weissen, wie der grauen, verteilte Entzündungsherde, die schon bei ganz oberffächlicher mikrosko- 
maioria, não mantêm relações diretas com as paredes dos vazos.

$\mathrm{Ha}$, é certo, zonas de infiltração leucocitaria, dispostas nas proximidades delles, e que, por vezes os envolvem completamente. A exame mais acurado e com auxilio de lentes mais poderozas, descobre-se o parazito em muitos dos citados pontos reacionarios.

Em numero variavel, quazi sempre incluzos em celulas de nucleo unico ou polimorfo, o esquizotripano aprezenta, em geral, a forma arredondada que já vimos nas lezões cardiacas.

Nas zonas inflamatorias, não é fato excecional verificar-se a prezença de celulas nervozas mais ou menos alteradas.

Tornou-se curiozo para nós verificar a diminuição numerica dos parazitos, na maioria de vezes, sua auzencia nos pontos nos quais a extensão do processo inflamatorio havia adquirido grande intensidade e abranjido vasta zona, em comparação com - outros, nas suas cercanias colocados, nos quais, percebendo-se o inicio da destruição do tecido hospedeiro, via-se o protozoario, variando apenas numericamente.

Estes fatos induziram-nos a concluir lojicamente pelo dezaparecimento do fator morbido in loco, ao aumentar da reação inflamatoria.

Observação mais pertinaz realizada no intuito de elucidar o ponto de orijem das infiltrações leucocitarias, esclareceu-nos em grande parte o cazo, mas não consideramos todo o assunto desvendado.

$\mathrm{Na}$ substancia branca medular encon trámos, como tipo, uma reunião de parazitos todos redondos, colocados dentro de uma celula enormemente aumentada de volume, sem que a menor reação inflamatoria se revelasse nesse ponto.

Retomámos o estudo dos córtes do nevraxe e verificámos a reprodução do fato referido em todo o sistema nervozo central. pischer Untersuchung hervortraten. Diese Herde, von sehr wechselnder Grösse und unregelmässiger Verteilung,stehen in keiner direkten Verbindung zu den Gefässwänden.

In ihrer Umgebung und manchmal dieselben vollständig umhïllend, finden sich freilich Zonen von Leukozyteninfiltration und bei eingehender Untersuchung mit stärkerer Vergrösserung erkennt man die Parasiten in vielen dieser Entzündungsherde.

Das Schizotrypanum erscheint in wechselnder Anzahl, fast immer in Zellen mit einzigem, einfachen oder polymorphen Kerne eingeschlosen und zeigt gewöhnlich die schon bei den Herzveränderungen erwähnte abgerundete Form.

Das Vorkommen mehr oder weniger veränderter Ganglienzellen in den Entzündungsherden wird nicht bloss ausnahmsweise beobachtet.

Es war mir interessant, festzustellen, dass an den Stellen, wo der Entzündungsprozess eine grosse Intensität und weite Ausdehnung erreicht hatte, die Parasiten seltener wurden und meistens verschwanden, im Gegensatz zu anderen, in der Nähe gelegenen, bei denen man erst den Anfang der Zerstörung der Wirtsgewebe sah und welche die Protozoen immer, wiewohl in wechselnder Zahl enthielten. Diese Tatsachen liessen logischer Weise darauf schliessen, dass der Krankheitserreger in Folge der zunehmenden Entzündungserscheinungen an Ort und Stelle verschwindet.

Zur Aufklärung des Ausgangspunktes der Leukozyteninfiltration machte ich eingehendere Beobachtungen, die mich über diesen Punkt ziemlich aufklärten; doch kann ich die Frage noch nicht als vollständig erledigt betrachten.

In der weissen Riickenmarkssubstanz findet man, typischer Weise, Anhäufungen ausschliesslich runder Parasiten, im Innern je einer enorm vergrösserten Zelle, ohne dass sich an der Stelle die geringste Entzïndungsreaktion vorfände. Zum Studium der Schnitte des Zentralnervensystems zurückkehrend, bestätigte ich die angeführte 
Julgamos daí que é esta uma das primeiras fazes do ataque contra o eixo cefalo-espinhal na molestia de ChaGas.

Vêm-se celulas redondas, com um unico nucleo, muito aumentado de volume, contendo em seu interior grande copia de esquizotripanos, sem que exista o minimo processo inflamatorio na vizinhança (Est. I5, Fig. I).

A celula parazitada julgamos ser sempre de nevroglia, mas esta afirmativa não póde ainda ser confirmada em absoluto com os estudos procedidos.

Leva-nos a esta propozição, isto é, a considerar a celula como de nevroglia, além da sua pozição no tecido, estrutura do seu nucleo, suas relações com os outros elementos, a circumstancia de nunca termos visto celula nervoza ou leucocito parazitado que não estivesse em fóco reacionario, emquanto que, neste cazo, ella fica izolada, córando-se com facilidade, e, como já dissemos, sem ataque por celulas migradoras.

Por divizões binarias sucessivas os parazitos aumentam numericamente, destroem o protoplasma, forçam a membrana a distender-se, hipertrofiando deste modo colossalmente o elemento anatomico que os contem.

Por vezes, mas o fato não chega a ser frequentemente observado, os esquizotripanos tornam-se flajelados ainda dentro da celula infestada (Est. I5, Fig. 4).

Esta verificação, tendo em consideração o que vimos já em outras celulas hospedeiras do parazito, induz-nos a crêr que a membrana da celula ou é perfurada pelo protozoario já flajelado, que no pensar de Chagas reprezenta a forma adulta, ou a rutura se dá pela pressão exercida pelos parazitos, de dentro para fóra.

Quer de um modo, quer de outro, realizado o fenomeno, é o ponto invadido por celulas reacionarias que para aí afluem em grande numero.

Nesta faze vêm-se celulas aí chegadas conterem 3, 4 e mais parazitos, ao lado de muitas outras inteiramente desprovidas del-
Beobachtung in seinem ganzen Verlaufe. Ich schloss daraus, dass es sich in diesem Falle von Chagas'scher Krankheit um die ersten Stadien der Invasion des Gehirnes und Rückenmarkes handle:

Man sieht runde, einkernige Zellen, welche in ihren Innern eine grosse Menge von Schizotrypanen enthalten, ohne dass sich in der Nachbarschaft der geringste Entzïndungsprozess auffinden liesse (Taf. I5, Fig. I).

Ich erachte, dass die invadierten Zellen der Neuroglia angehören, doch genügen die bisherigen Untersuchungen nicht, um diese Behauptung absolut sicher $\mathrm{zu}$ machen. Für Neurogliazellen halte ich sie nicht nur wegen ihrer Lage im Gewebe, ihrer Kernstruktur und ihren Beziehungen $z u$ anderen Elementen, sondern auch wegen des Umstandes, dass ich, ausserhalb von Entzündungsherden, niemals parasitenhaltige Ganglienzellen oder Leukozyten gesehen habe, während diese Zellen isoliert, gut färbbar und ohne Beziehung zu Wanderzellen erscheinen.

Die Parasiten vermehren sich durch successive Zweiteilung, zerstören das Protoplasma und dehnen die Membran derart, dass eine kolossale Hypertrophie der sie enthaltenden Zelle entsteht.

Zuweilen erhalten die Parasiten Geisseln, während sie noch in der befallenen Zelle eingeschlossen sind, doch ist dies nicht eben häufig (Taf. 15, Fig. 4). In Berïcksichtigung dessen, was wir bereits an anderen parasitenhaltigen Zellen beobachteten, fuihrt mich diese Beobachtung zu der Annahme, dass die Zellmembran entweder durch bereits geisseltragende (nach ChaGas erwachsene) Flagellaten perforiert wird, oder dass die Ruptur, in Folge des inneren, durch die Parasiten ausgeubten Druckes, zu Stande kömmt.

Wenn dieses Ereignis eintritt, gleichviel wie, so wird die Stelle von einer grossen Anzahl herbeiströmender Wanderzellen invadiert. Man sieht jetzt die hier angesammelten Zellen drei, vier und mehr Parasiten beherbergen, während viele andere völlig frei erscheinen. In solchen 
les. Nestes fócos dá-se o dezaparecimento do parazito com o progredir da reação, conforme referimos antes.

Do que observámos parece podermos afirmar que o tripanozomida penetra na celula, multiplica-se por divizão binaria, rompe a membrana e sái, motivando nessa ocazião reação grande, na qual, não raro, perecem celulas nervozas.

Estes fatos foram verificados em todo o sistema nervozo do cazo agudo, predominando os elementos parazitados e os fócos de reação nos nucleos centrais, protuberancia e medula.

Entretanto, no cerebelo apenas encontrámos fócos inflamatorios, mas não vimos celulas cheias de parazitos.

$O$ processo inflamatorio meninjeano assemelha-se bastante ao seu similar nas outras tripanozomiazes.

Nas arterias que irrigam a substancia nervoza encontram-se, em muitas dellas, fenomenos francos de peri-arterite.

$\mathrm{Ha}$, portanto, na molestia de ChaGaS meningo-encefalo-mielite.

Os elementos constituitivos destes dois processos, e as alterações dos elementos nervozos serão estudados em trabalho posterior a este.

\section{GLANDULAS.}

Multiplas são as alterações acarretadas para estes organs pela molestia de Chagas.

As observações clinicas do descobridor desta nova entidade morbida, mostram que ha sempre, em todos os cazos, lezões importantes neste sistema organico e que, em muitos delles, o quadro morbido gira em torno da alteração funcional do parenquima de determinada glandula.'

Não falando da tireoide que Chagas encontrou sempre lezada, quer no inicio, quer durante a evolução da molestia, em centenas de cazos, outras glandulas mostram tambem alterações funcionais muito importantes.
Herden erfolgt das Verschwinden des $\mathrm{Pa}$ rasiten mit fortschreitender Reaktion, wie ich schon oben auseinandersetzte.

Aus diesen Beobachtungen kann man, wie ich glaube, den Schluss ziehen, dass das Trypanosoma in die Zelle eindringt, sich dort durch Zweiteilung vermehrt, die Membran sprengt und schliesslich austritt, wobei eine starke Reaktion hervorgerufen wird, bei welcher nicht selten Nervenzellen. zu Grunde gehen.

Diese Befunde wurden im ganzen zentralen Nervensystem des akuten Falles erhoben, wobei befallene Zellen und Erzündungsherde besonders vorwiegend in den zentralen Kernen, Pons und Rückenmark gefunden wurden.

Im Kleinhirn habe ich iibrigens nur Entzündungsherde gefunden, in denen keine parasitenhaltige Zellen vorkamen.

Die Entzündung der Meningen stellt einen, demjenigen bei anderen Trypanosomiasisarten sehr ähnlichen, Prozess vor.

Bei vielen der Arterien, welche die Nervensubstanz versehen, erkennt man leichte periarteriitische Erscheinungen.

Man findet also bei der Krankheit von Chagas eine Meningo-encephalo-myelitis. Die Vorgänge bei diesen Prozessen und die Veränderungen an den Elementen des Nervensystems sollen in einer späteren Arbeit studiert werden.

\section{DRÜSEN.}

Die Veränderungen, welche die Schizotrypanose in den drüsigen Organen herbeiführt, sind mannigfacher Natur.

Die klinischen Beobachtungen des Entdeckers dieser neuen Krankheitseinheit zeigen, dass, in dieser Gruppe von Organen, bei allen Fällen wichtige Veränderungen vorkommen und dass bei vielen das Krankheitsbild sich um Funktionsstörungen des Parenchymes einer bestimmten Drüse dreht.

Es war mir bei meinen Studien unmöglich, dieses Thema zu arschöpten und die Veränderungen sämmtlicher Drüsen aufzuklären. 
Não nos foi possivel levar o nosso. estudo a cabo neste assunto, deixando perfeitamente elucidadas as lezões de todas as glandulas.

Trataremos apenas da tireoide, capsula supra-renal, ovario e testiculo, assinalando descle já que verificámos a reação inflamatoria no rim, hipofize e glandula parotida de animais infetados.

Tireoide. - Nos cazos agudos da molestia verifica-se pela palpação o endurecimento da glandula.

Nos córtes ha pontos inflamatorios no tecido conjuntivo do orgam e escleroze muito pronunciada em alguns cazos.

As veziculas tireoidianas mostram-se diminuidas de volume, algumas mesmo com a luz muito reduzida.

Raras são as veziculas, na tireoide esclerozada, que aprezentam cavidades medianamente constituidas, e a substancia coloide que existe em seu interior, em muitas, é modificada em sua cromofilia.

As celulas glandulares em certas veziculas destacam-se em grande numero, sendo encontradas na substancia coloide.

Este fato verifica-se com facilidade em glandulas de animais nas quais as celulas destacadas se aprezentam muito dejeneradas.

As ilhotas epiteliais que normalmente existem entre as veziculas tireoidianas, aparentam haver sofrido multiplicação de suas celulas.

Estas massas epiteliais existem profuzamente disseminadas e, em muitas veziculas, prolongam-se por toda a superficie.

Em cazos cronicos ha fócos fibrozos de grande extensão no interior da glandula e os fócos inflamatorios são muito pronunciados em alguns pontos da tireoide.

Muitos destes fócos são portadores de cistos de volume variavel e de conteúdo diverso: uns são pequenos, de substancia coloide; outros desta mesma substancia,
Abgesehen:von der Thyreoidea, welche Chagas immer verändert fand, ebensowohl im Beginne, als während des Verlaufes von Hunderten von Krankheitsfällen, zeigen auch andere Drüsen sehr wichtige Funktionsstörungen.

Ich werde nur Schilddruise, Nebennieren, Ovarien und Hoden besprechen, betone aber schon jetzt, dass ich eine enzündliche Reaktion auch in den Nieren, der Hypophyse und den Ohrspeicheldrüsen beobachtet habe.

Schilddrüse: In akuten Fällen konstatiert man durch Palpation die Verhärtung der Drüse.

Auf Schnitten findet man im Bindegewebe dieses Organes entzündete Stellen und in manchen Fällen eine sehr ausgesprochene Sklerose. Die Schilddrüsenbläschen erscheinen sehr verkleinert und einige zeigen selbst ein sehr reduziertes I,umen.

Bei der sklerotischen Schilddrüse zeigen nur wenige Bläschen mittelgrosse Höhlungen und die in ihrem Innern vorhandene Kolloidsubstanz ist oft in ihrer Färbbarkeit verändert.

In manchen Bläschen lösen sich zahlreiche Drüsenzellen ab und werden in der Kolloidsubstanz gefunden. Diese Tatsache beobachtet man leicht bei den Drüsen von Tieren, bei welchen die abgelösten Zellen stark degeneriert erscheinen.

Die Epithelinseln, welche normalerweise zwischen den Schilddrüsenbläschen vorkommen, scheinen eine Vermehrung der Zellen zu erleiden.

Diese Epithelialmassen kommen reichlich zerstreut vor und erstrecken sich in vielen Bläschen über die ganze Oberfläche.

Bei chronischen Fällen trifft man sehr ausgedehnte fibröse Herde im Innern der Drüse und an manchen Stellen derselben sind die Entzündungsherde sehr ausgesprochen.

Viele dieser Herde zeigen Zysten von wechselnder Grösse mit verschiedenem Inhalte: einige sind klein und kolloidhaltig; andere, jedoch viel grössere, ent- 
mas de volume bastante grande, e ainda outros contendo liquido e cujas paredes são, em parte ou totalmente, calcificadas.

$\mathrm{Ha}$, entretanto, cazos cronicos, nos quais não se verifica a formação de cistos, revelando então a glandula grande quantidade de tecido epitelial intervezicular, escleroze e veziculas pequenas e alteradas.

Nessas glandulas os vazos sofrem processos histopatolojicos semelhantes aos que foram encontrados nos vazos do coração.

Capsula supra Renal. - E' orgam bastante lezado nesta molestia, extendendose a lezão a todas as camadas da glandula.

Em um cazo cronico da molestia, de forma cardiaca, o Dr. ChaGAs rejistou a coloração bronzea da pele, como provavel consequencia de lezões das capsulas suprarenais.

$\mathrm{Na}$ autopsia, estes organs estavam aumentados de volume, aprezentavam, ao córte, a camada medular muito acrecida e de um branco mate.

Córtes destes organs mostram, quer na camada cortical, quer na medular, lezões de celulas glandulares e fócos inflamatorios. A persistencia destas lezões foi por nós verificada em outros cazos, com outras formas, da molestia de CHAGAS.

E' possivel que o parazito penetre nas celulas glandulares, se multipliquem e, acarretando a destruição dellas, provoque a reação inflamatoria.

Esta propozição, que só em hipoteze podemos estabelecer para os cazos humanos, já foi verificada em animais de experiencia, como se póde ver no dezenho dum orgam de cobaia, em uma celula da camada faciculada (Estampa I5, Fig. 2).

As lezões vasculares inflamatorias nestes organs são identicas ás que foram já assinaladas.

Ovario. - Nossas observações neste orgam utilizaram o material dum cazo cronico humano, e de varios animais infetados. halten dieselbe Substanz; noch andere enthalten zwar Flüssigkeit, aber ihre Wandung ist ganz oder teilweise verkalkt.

Es gibt aber auch chronische Fälle, bei denen man keine Zystenbildung findet und die Drüse eine grosse Menge von intravesikulären Epithelien, Skleroseherden und kleinen veränderten Bläschen aufweist.

In diesen Drüsen erleiden die Gefässe ähnliche histo-pathologische Veränderungen, wie sie bei den Herzgefässen gefunden wurden.

Nebenniere. - Dieses Organ ist bei unserer Krankheit ziemlich verändert und die Läsionen erstrecken sich auf alle Schichten der Drüse.

In einem chronischen, von Herzerscheinungen begleiteten, Falle dieser Krankheit verzeichnete Dr. ChaGas eine Bronzefärbung der Haut als wahrscheinliche Folge von Veränderungen der Nebennieren.

Bei der Autopsie fand man diese Organe vergrössert und auf dem Schnitte erschien die Markschicht sehr verbreitert und mattweiss.

Mikroskopische Schnitte zeigen, sowohl in der Rindenschicht, als auch im Marke, Veränderungen der Drüsenzellen und entzündliche Herde. Das Bestehen solcher Veränderungen wurde von mir bei anderen Formen der neuen Krankheit festgestellt.

Es ist möglich, dass der Parasit in die Drüsenzellen eindringt und durch seine Vermehrung ihre Schädigung herbeiführt, welcher die entzündliche Reaktion folgt. Dieser Satz, den ich beim Menschen nur als Vermutung aufstellen kann, wurde schon an Versuchstieren konstatiert, wie man aus der Abbildung sieht, die eine Zelle aus der Fasciculärschicht zeigt (Taf. I5, Fig. 2).

Auch in diesem Organe sind die Entzündungserscheinungen an den Gefässen den bereits geschilderten ähnlich.

Ovarium. - Bei meinen Untersuchungen dieses Organes verwandte ich das $\mathrm{Ma}$ terial von einer chronischen Krankheits- 
No cazo humano eram ambos os ovarios portadores de volumozo cisto coloide, limitado por um tecido esclerotico.

A glandula toda, quer na parte central, quer na periferica, era séde de reação inflamatoria e de escleroze.

Em animais verificámos alguns cistos de pequeno tamanho, com substancia cromaticamente comparavel á substancia mucoide.

Em redor delles havia tecido inflamatorio e, algumas vezes, esclerozante.

Possuiam foliculos normais em todas as fazes evolutivas e, raramente, os encontrámos muito lezados.

Não verificámos a prezença do esquizotripano nesses organs, mesmo nos que aprezentavam maior reação inflamatoria.

Os vazos, por vezes, revelavam-se inflamados.

Testiculo. - Todo o nosso trabalho sobre esta glandula foi feito em organs de cobaias infetadas, pois não lográmos obter ainda material humano.

$\mathrm{Na}$ esquizotripanoze da cobaia o testiculo é um dos organs mais sériamente lezados pelo germen da molestia.

As lezões abranjem não só a parte nobre da glandula genetica, como a interstical, e os envolucros. Os tubos seminais mostram-se, em quazi todos os cazos, com gráos varios de alterações.

Assim é que, ao mais superficial exame, detem a nossa atenção o aspeto de tubos glandulares, reduzidos a uma unica camada de celulas alteradas e diversamente córadas em relação ás de outros tubos.

Revelaram-se mais, em varios pontos, zonas de orquite, ao mesmo tempo que outros pontos se conservavam integros.

Sob observação mais atenta, melhor se vêm tubos que se aprezentam sem a menor alteração estrutural, ao lado de outros cujas alterações são enormes. form des Menschen und verschiedene infizierte Tiere.

Beim Menschen fand sich in beiden Ovarien eine volumöse Kolloidzyste, die von sklerotischem Gewebe begrenzt war.

Die ganze Drüse, sowohl in der Peripherie, wie im Zentrum, war der Sitz entzündlicher Reaktion und Sklerosierung.

Bei Tieren konstatierte ich einige. Zysten von geringer Grösse, deren Inhalt bei der Färbung sich der Schleimsubstanz ähnlich verhielt. Um diese fand sich entzündliches und manchmal sklerotisches Gewebe. Die Ovarien zeigten normale Follikel in allen Entwicklungsstadien und nur selten fand ich dieselben deutlicli geschädigt. Die Gegenwart des Schizotrypanum konnte in diesen Organen nicht konstatiert werden, selbst dann, wenn die entzündliche Reaktion sehr hochgradig war.

Die Gefässe zeigten zuweilen Entzündungserscheinungen.

Testrkel. - Alle meine Studien iiber diese Drüsen wurden an Organen von infizierten Meerschweinchen angestellt, da es mir nicht gelang, menschliches Material zu erhalten.

Bei der Schizotrypanose des Meerschweinchens ist der Hoden eines der durch den Krankheitserreger am schwersten geschädigten Organe.

Die Läsionen umfassen nicht nur den Druisenteil desselben, sondern auch das interstitielle Gewebe und die äusseren Hüllen. An den Samenkanälchen sieht man fast in allen Fällen Veränderungen verschiedenen Grades.

So wird, auch bei der oberflächlichsten Untersuchung, die Aufmerksamkeit durch die Erscheinung von Kanälchen gefesselt, welche auf eine Schicht veränderter und sich anders färbender Zellen reduziert sind.

Es zeigen sich an verschiedenen Stellen Herde von Orchitis, während gleichzeitig andere Stellen intakt erscheinen.

Bei genauerer Untersuchung erkennt man noch deutlicher Kanälchen ohne 
Nas glandulas espermaticas atacadas pelo esquizotripano, canais seminiferos existem com multiplas porções de sua parede em perfeita atividade, ao passo que em outras ha celulas muito aumentadas de volume, cheias de parazitos, geralmente redondos mas, por vezes, já flajelados.

Em córtes seriados deste orgam, vêmse tubos que em uns córtes aprezentam estrutura integra, em outros alterada.

$\mathrm{Ha}$ mesmo tubos que apenas tem uma ou outra forma parazitaria, no interior ou fóra de celulas da parede, por vezes em divizão.

Certamente será esta a primeira faze da infestação testicular.

As celulas que no tubo mais vezes : por maior numero, se encontram parazitadas são as da camada bazal, mas o processo agressivo não lhes é restrito, podendo invadir todas as outras celulas, até mesmo as da camada superior.

Vezes ha, nas quais os elementos hospedeiros se destacam da parede, mais ou menos cheios de parazitos, são levados até a luz tubular e, de lá, acarretados pelo liquido espermatico.

Nestes elementos hospedeiros vêm-se apenas o nucleo, a membrana e, dentro della um numero enorme de esquizotripanos.

A fig. I da estampa 16 reprezenta o córte obliquo dum canal, córado pelo metodo de Giemsa, mostrando o que acabamos de referir.

Além disso vêm-se parazitos izolados e celulas completamente dejeneradas, com enorme quantidade de esquizotripanos no seu interior.

A proporção que a infestação progride á custa da reprodução dos parazitos, rutura das celulas e parazitação de outras, jegliche Ånderung der Struktur, neben solchen, welche enorme Veränderungen aufweisen.

Bei den vom Schizotrypanum befallenen Samendrüsen finden sich Samenkanälchen, bei denen viele Portionen der Wandung in voller Tätigkeit begriffen sind, während in anderen die Zellen sehr vergrössert und von Parasiten erfüllt sind; letztere sind gewöhnlich rund, manchmal aber bereits mit Geisseln versehen. In Serienschnitten durch dieses Organ sieht man Kanälchen, welche in einigen Schnitten normale, in andern pathologische Struktur zeigen. Es finden sich auch Tuben, welche nur eine oder andere parasitäre Form, manchmal in Teilung begriffen, im Innern oder ausserhalb der Wandzellen aufweisen. Gewiss repräsentiert dies die erste'Phase der Hodeninfektion.

Die Zellen, welche in den Kanälchen am häufigsten und zahlreichsten befallen werden, sind diejenigen der Basalschicht; doch beschränkt der Prozess seine Angriffe nicht auf diese allein, vielmehr kann er alle anderen Zellen, auch die der oberflächlichen Schicht befallen.

Es kommt vor, dass die infizierten Zellen sich, mehr oder weniger voll von Parasiten, von der Wandung ablösen, ins Lumen der Tubuli gerathen und von da mit der Samenflüsigkeit weiter geführt werden.

In solchen infizierten Zellen sieht man nur den Kern und die Membran, sowie im Innern der letzteren eine ungeheure Zahl von Schizotrypanumformen.

Fig. I, Taf. I6 zeigt einen, nach GrEMSA gefärbten Schrägschnitt durch ein Kanälchen, welcher das geschilderte illustriert. Ausserdem sieht man isolierte $\mathrm{Pa}$ rasiten und vollständig degenerierte Zellen mit einer enormen Menge von Krankheitserregern in ihrem Innern.

In dem Maasse, wie die Infektion durch Vermehrung der Parasiten, Ruptur der Zellmembranen und Infektion neuer Zellen fortschreitet, verliert das Kanälchen 
o tubo glandular sofre perda de elementos da sua parede, ficando por fim reduzido a uma unica camada de celulas e estas mesmo em dejeneração.

Neste estado a prezença de parazitos é raramente verificada e não existem fenomenos de reprodução celular tendentes á separação das lezões.

Ao lado deste processo descrito, passa-se outro, mas este no tecido de sustentaculo da glandula.

Perifericamente aos canais, sem ser, comtudo, extenso a toda a glandula, ha aumento numerico de celulas conjuntivas e infiltração leucocitaria.

Esta reação pericanalicular afeta não somente tubos parazitados ou já em caminho de destruição, mas tambem tubos integros.

Convém assinalar, entretanto, que ha rejiões nestas glandulas, nas quais não foi verificado o menor esboço de reação, mesmo ao redor de canais vitimas do protozoario.

Algumas vezes o processo inflamatorio é bastante intenso nas cercanias de tubos muito lezados, rompe a membrana conjuntiva e leva a destruição ao que resta da parede tubular.

Aí forma-se então grande acumulo de celulas reacionarias, vendo-se, de permeio com ellas, celulas epiteliais em destruição, e parazitos, uns ainda no interior destas celulas, outros fagocitados por aquellas, e ainda outros, mais raros, completamente livres.

As celulas reacionarias destes fócos são, em sua maioria uninucleadas e com pequena camada de protoplasma.

No tecido conjuntivo encontram-se celulas de tamanho gigantesco, hospedeiras de parazitos, que, em seu interior, podem ser contados por centenas. Tais celulas possuem nucleo bastante grande, na maioria das vezes alterado, e tem protoplasma tomado pelos parazitos.

Na maioria dos cazos seu contorno é cercado por laminas conjuntivas, achandose ellas em zonas inflamatorias.
Elemente seiner Wandung und wird auf eine einzige Schicht von - selbst in Degeneration begriffenen - Zellen reduziert. In diesem Stadium wird die Gegenwart der Parasiten selten konstatiert und es existieren keine Erscheinungen einer Zellreproduktion, welche zu einer Ausgleichung der Schädigung dienen könnte.

Neben dem beschriebenen Prozesse verläuft ein anderer im Stützgewebe der Drüse. Peripherisch von den Kanälchen, ohne sich jedoch auf die ganze Drüse zu erstrecken, existiert eine Vermehrung der Bindegewebszellen und eine Infiltration mit Leukozyten.

Diese perikanalikuläre Reaktion befällt nicht nur parasitenhaltige oder im Untergang begriffene, sondern auch normale Tubuli.

Es muss jedoch hervorgehoben werden, dass in diesen Drüsen Stellen vorkommen, wo nicht die geringste Andeutung einer Reaktion gefunden wird, selbst um $\mathrm{Ka}$ nälchen, welche von den Protozoen befallen sind.

Manchmal ist der Entzündungsprozess um stark geschädigte Kanälchen ein sehr lebhafter, so dass er die Bindegewebsmembran zerreisst und den Rest der Kanälchenwand zerstört. Es bildet sich dann daselbst eine grosse Anhäufung reaktiver Zellen, zwischen denen man, im Untergang begriffene, Epithelien und $\mathrm{Pa}$ rasiten, teils im Innern jener Zellen und von ihnen aufgenommen, teils, aber selten, vollkommen frei erkennen kann. Die reaktiven Zellen solcher Herde sind der Mehrzahl nach einzellig und haben eine geringe Protoplasmaschicht.

Im Bindegewebe finden sich noch Zellen von riesiger Grösse mit Hunderten von Parasiten im Innern. Solche Zellen haben einen ziemlich grossen Kern, der meistens stark geschädigt ist und in seinem Protoplasma Parasiten enthält. Ihr Umriss ist meist von Bindegewebsschichten begrenzt und sie finden sich in entzündeten Gebieten. Ich halte sie für interstitielle Zellen; um diese Vermutung 
Julgamol-as celulas intersticiais mas precizamos de pesquizas em animais propicios ao estudo da glandula intersticial do testiculo, para transformar este juizo em afirmativa (Est. I5, Fig. 3)

Os vazos, em grande numero, são passivos de lezões identicas ás que assinalámos em outros organs. $\mathrm{Na}$ albujinea não encontrámos fenomenos inflamatorios mas vimos celulas hipertrofidas e intensamente parazitadas (Est. 16, Fig. 2).

EPIDIDImo: Em córtes deste orgam tivemos ensejo de verificar, na luz tubular, de mistura com espermatozoides, celulas parazitadas e semelhantes ás que acima mencionámos como destacadas das paredes dos canais seminiferos.

$\mathrm{Ha}$ aí outras celulas infestadas cuja orijem não nos é possivel ainda estabelecer; algumas tem volume bastante reduzido, em media diametral 15 a 20 micra; outras, porém, ultrapassam de muito esta média.

Vêm-se, algumas vezes, massas protoplasmaticas, sem nucleo vizivel, e com muitos esquizotripanos.

O estudo de córtes seriados mostra facilmente serem estas partes constitutivas das grandes celulas a que antes nos referimos.

Por vezes encontram-se protozoarios livres no liquido, mas este fato não é comum.

Quando faziamos as nossas pesquizas microscopicas, tivemos ocazião de observar duas formas redondas do esquizotripano parecendo incluidas no segmento cefalico de um espermatozoide (Est. r6, Fig. 3).

Esta celula mostra dois vacuolos correspondendo aos parazitos, alteração do nucleo e a modificação, não só morfolojica, mas tambem cromatica do "Nebenkern".

Uma unica vez se nos deparou á observação, este fato, e, por isso, deixamos para estudo posterior a parazitação da referida celula. zur Sicherheit zu gestalten, brauche ich aber Untersuchungen an Tieren, die für das Studium des interstitiellen Hodengewebes guinstiger sind (Fig. 3, Taf. I5).

Zahlreiche Gefässe erleiden dieselben Veränderungen, die ich bei anderen Organen angegeben habe. In der albuginea fand ich keine Entziindungserscheinungen, dagegen hypertrophische und intensiv infizierte Zellen (Taf. I6, Fig. 2).

Epididymys: In Schnitten dieses Organes konstatierte ich im Lumen der Kanälchen unter den Spermatozoen ähn- liche parasitenhaltige Zellen, wie ich sie eben als von der Mündung der Samenkanälchen abgelöst beschrieb.

Es kommen hier auch andere infizierte Zellen vor, deren Abstammung ich noch nicht feststellen konnte; einige sind sehr klein und messen im Mittel r $^{--20}$ Mikra; andere dagegen überschreiten diese mittlere Grösse weit.

Manchmal sieht man Protoplasmamassen ohne erkennbaren Kern, welche viele Schizotrypanen enthalten. Das Studium von Serienschnitten zeigt. ohne weitere Schwierigkeiten, dass dies Fragmente der oben geschilderten grossen Zellen sind.

Manchmal findet man auch Protozoen in der Flüssigkeit, doch kömmt dies nicht häufig vor.

Während meiner Untersuchungen hatte ich Gelegenheit zwei runde Schizotrypanumformen $z u$ beobachten, welche im Kopfteil eines Spermatozoons eingeschlossen schienen (Taf. I6, Fig. 3). Diese Zelle zeigt zwei Vacuolen, welche Parasiten entsprechen, Veränderung des Kernes, sowie eine, nicht nur morphologische, sondern auch chromatische Modifikation des Nebenkernes.

Dieses Faktum kam nur einmal zur Beobachtung und deshalb verspare ich die Infektion dieser Zellen für ein späteres Studium. Weitere Untersuchungen können jeden $Z$ weifel zerstreuen, doch ist die Degeneration des Spermatozoons ein gewich- 
Novas pesquizas poderão dissipar duvidas, si bem que a dejeneração sofrida pelo espermatozoide seja poderozo elemento para afirmar a sua parazitação.

Esperma. - Quando se sacrifica a cobaia por picada no bulbo ou no coração, não raro se dá a expulsão de algumas gotas de esperma que, neste cazo, é puro.

Colhemos assim o liquido em animais infetados, e o exame revelou, 2 vezes em 6 , a prezença do esquizotripano.

Manguinhos, Julho de I9ir. tiger Grund; um seine Infektion $\mathrm{zu}$ behaupten.

Sperma. - Wenn man Meerschweinchen durch Stich ins verlängerte Mark oder ins Herz tötet, so erfolgt nicht selten die Entleerung einiger Tropfen, in diesem Falle ganz reinen, Samens. Ich habe auf diese Weise die Flüssigkeit von infizierten Tieren gewonnen und die Untersuchung ergab in zwei von sechs Fällen die Gegenwart des Schizotrypanums.

Manguinhos, Juli IgI I.

\section{ESTAMPA 14.}

Fig.

I. Corte lonjitudinal de musculo estriado de cobaia. Coloração van Gieson-Curtis. Aumento $=1363$ diametros.

a) nucleos das celulas musculares.

b) formas redondas de esquizotripanos.

c) formas redondas de esquizotripano em divizão.

2. Corte transverso de fibra muscular estriada de cobaia, contendo esquizotripanos na parte central. Coloração VAN GIESON-CURTIS. Aumento $=\mathrm{I}_{3} 63$ diametros.

a) nucleo da fibra.

b) forma redonda de esquizotripano.

c) esquizotripano em divizão.

3. Corte transverso de fibra muscular estriada em um ponto onde já existe rutura da membrana. Coloração vaN Gieson-CuRTis. Aumento $=1_{3}{ }_{3}$ diametros.

a) nucleo da fibra.

b) forma redonda de esquizotripano.

c) esquizotripano em divizão.

d) forma flajelada do parazito.

4. Neste corte ve-se destruição do elemento muscular e a prezença de varios parazitos flajelados. Coloração vaN Gieson-Curtis. Aumento $=1363$ diametros.

a) nucleo da fibra.

b) substancia hialina rezultante da destruição do elemento muscular.

c) formas redondas de esquizotripano.

d) forma flajelada de esquizotripano.

\section{ESTAMPA 15.}

Fig.

Corte de cerebro onde se vê uma celula de nevroglia contendo um cisto de formas redondas de esquizotripano. Coloração GiEMSA. Aumento $=1_{3} 6_{3}$ diametros.

a) celula nervoza.

b) celula de nevroglia.

c) celula de nevroglia aumentada de volume e cheia de formas redondas de esquizotripano.

d) nucleo da celula.

e) formas redondas de esquizotripano.
TAFEL 14.

Fig.

I. Längsschnitt durch quergestreiften Meerschweinchenmuskel. Färbung nach VAN Gieson-Curtis. Vergr. $=\mathbf{r}_{3} \mathbf{6}_{3}$.

a) Kerne des Muskelzellen.

b) Runde Formen des Schizotrypanum.

c) Dieselben in Teilung.

2. Querschnitt einer quergestreiften Muskelfaser, welche im Innern Schizotrypanum enthält. Färbung nach VAN GIESON-

CURTIS. Vergr. $=1363$.

a) Kern der Faser.

b) Runde Formen des Schizotrypanum.

c) Schizotrypanum im Teilung.

3. Querschnitt der quergestreiften Muskelfaser an einer Stelle, wo bereits eine Ruptur vorliegt. Färbung nach vaN Gieson.Curtis. Vergr. $=1363$

a) Kern der Faser.

b) Runde Formen des Schizotrypanum.

c) Schizotrypanum im Teilung.

d) Geisseltragende Form des Parasiten.

4. In diesem Schnitte sieht man die Zerstörung des Muskelelementes und verschieden geisseltragende Parasiten. Färbung nach vaN GIESON-CURTIS. Vergr.= I 363 .

a) Kern der Faser.

b) Hyaline Substanz als Folgezustand der Zerstörung der Muskelfaser.

c) Runde Formen des Schizotrypanum.

d) Geisseltragende Formen des Schizo. trypanum.

TAFEL 15.

Fig.

r. Hirnschnitt mit einer Neurogliazelle, welche eine von runden Formen des Schizotrypanum erfülte Zelle bildet. GiemsAfärbung. Vergr. $=r_{3}{ }^{6} 3$.

a) Ganglienzelle.

b) Neurogliazelle.

c) Vergrösserte und von runden Formen des Schizotrypanum erfüllte Neurozelle.

d) Zellkern.

c) Runde Formen des Schizotrypanum. 
Fig.

2. Corte de capsula suprarenal de cobaia zona faciculada. Coloração VAN GIEsonCurtis. A"mento $=1_{3} 6_{3}$ diametros.

a) celula da zona faciculada.

b) celula intersticial.

c) celula interfacicular.

d) celula da zona faciculada contendo formas redondas do parazito.

e) nucleo da celula parazitada.

f) formas redondas de esquizotripano.

3. Celula intersticial hipertrofiada de testiculo de cobaia. Coloração van GIEsonCURTis. Aumento $=$ r200 diametros.

a) nucleo da celula.

b) laminas conjuntivas pericelulares.

c) formas redondas de esquizotripano.

d) esquizotripano com nucleo em divizão.

e) elementos de reação.

4. Corte de cerebro onde ha um cisto de esquizotripanos no interior de uma celula de nevroglia, sendo a maioria constituida de elementos flajelados. Coloração GrEmsa. Aumento $=\mathrm{r}_{3} 6_{3}$ diametros.

a) celula de nevroglia.

b) capilar sanguineo com nucleo da celula endotelial.

c) celula contendo esquizotripanos flajelados.

d) nucleo da celula parazitada.

e) formas redondas do parazito.

f) formas flageladas de esquizotripano.

\section{ESTAMPA $\mathbf{6} 6$.}

Fig.

r. Corte obliquo de um tubo seminifero de cobaia colorido pelo metodo de GIEMSA. Aumento $=1200$ diametros.

a) espermatozoides.

b) celulas glandulares em cariocineze.

c) celula epitelial, destacada da parede, contendo numerozas formas redondas de esquizotripano e com dejeneração nuclear muito pronunciada.

d) esquizotripanos em divizão.

e) celula da camada parietal cheia de esquizotripanos.

f) parazitos no interior de celulas em via de destruição.

g) parede do tubo vizinho.

h) tecido intertubular.

2. Corte da albujinea de cobaia onde se ve uma grande celula, completamente cheia de esquizotripanos. Coloração Giemsa. Aumento $=1200$ diametros.

a) nuclèo da celula.

b) formas redondas de esquizotripano.

3. Espermatozoides do interior de um tubo epididimario, sendo um delles parazitado. Coloração Giemsa. Aumento ${ }_{13} 6_{3}=$ dia. metros.

a) espermatozoides.

b) segmento cefalico com duas formas redondas de esquizotripano, certamente em seu interior.
Fig.

2. Schnitt durch die Nebenniere eines Meerschweinchens. Fassiculäre Zone. Färbung nach VAN GIESON-CURTIS. Vergr. $=1363$.

a) Zelle der fasciculären Zone.

b) Interstitielle Zelle.

c) Interfasciculäre Zelle.

d) Zelle der fasciculären Zone, welche runde Parsitenformen einschliesst.

e) Kern einer parasitenhaltigen Zelle.

f) Runde Formen des Schizotrypanum.

3. Hypertrophische interstitielle Zelle aus dem Hoden eines Meerschweinchens. Färbung nach vaN GIEsON-CuRTIs. Vergr.= 1200.

a) Zellkern.

b) Perizelluläre Bindegewebslamellen.

c) Runde Schizotrypanumformen.

d) Schizotrypanum mit in Teilung begriffenem Kerne.

e) Entzündliche Elemente.

4. Hirnschnitt mit einer Schizotrypanumzyste im Innern einer Neurogliazelle, welche grösstenteils aus geisseltragenden Elementen besteht. GremSafärbung. Vergr. $=\mathbf{r}_{3} 6_{3}$.

a) Neurogliazelle.

b) Blutkapillare mit dem Kern einer, Endothelialzelle.

c) Zelle mit geisseltragenden Schizotrypanum formen.

d) Kern der narasitenhaltigen Zelle.

e) Runde Formen der Parasiten.

f) Geisseltragende Formen des Schizotrypanum.

TAFEL 16 .

Fig.

I. Schrägschnitt durch ein Samenkanälchen vom Merschweinchen. Färbung nach Gremsa. Vergr. $=1200$.

a) Spermatozoen.

b) Drüsenzellen in Karyokinese.

c) Von der Wandung abgelöste Epithelialzelle, die im Innern zahlreiche runde Schizotrypanumformen enthälte. Sehr deutliche Kerndegeneration.

d) Schizotrypanen in Teilung.

e) Mit Schizotrypanen erfüllte Zelle aus der Parietalschicht.

f) Parasiten aus dem Innern in Zerstö. rung befindlicher Zellen.

g) Wandung des benachbarten Kanälchens.

h) Intertubuläres Gewebe.

2. Schnitt durch die Albuginea vom Meerschweinchen. Man sieht eine grosse, von Schizotrypanen ganz erfüllte Zelle. GHEMSAfärbung. Vergr. $=1200$.

a) Zellkern

b) Runde Schizotrypanumformen.

3. Spermatozoen im Innern eines Nebenhodenkanälchens; eines derselben enthält einen Parasiten. GremsAfärbung. Vergr. $=1363$.

a) Spermatozoen.

b) Kopfabschnitt eines solchen mit zwei, sicher in seinem Innern gelegenen, runden Schizotrypanumformen 

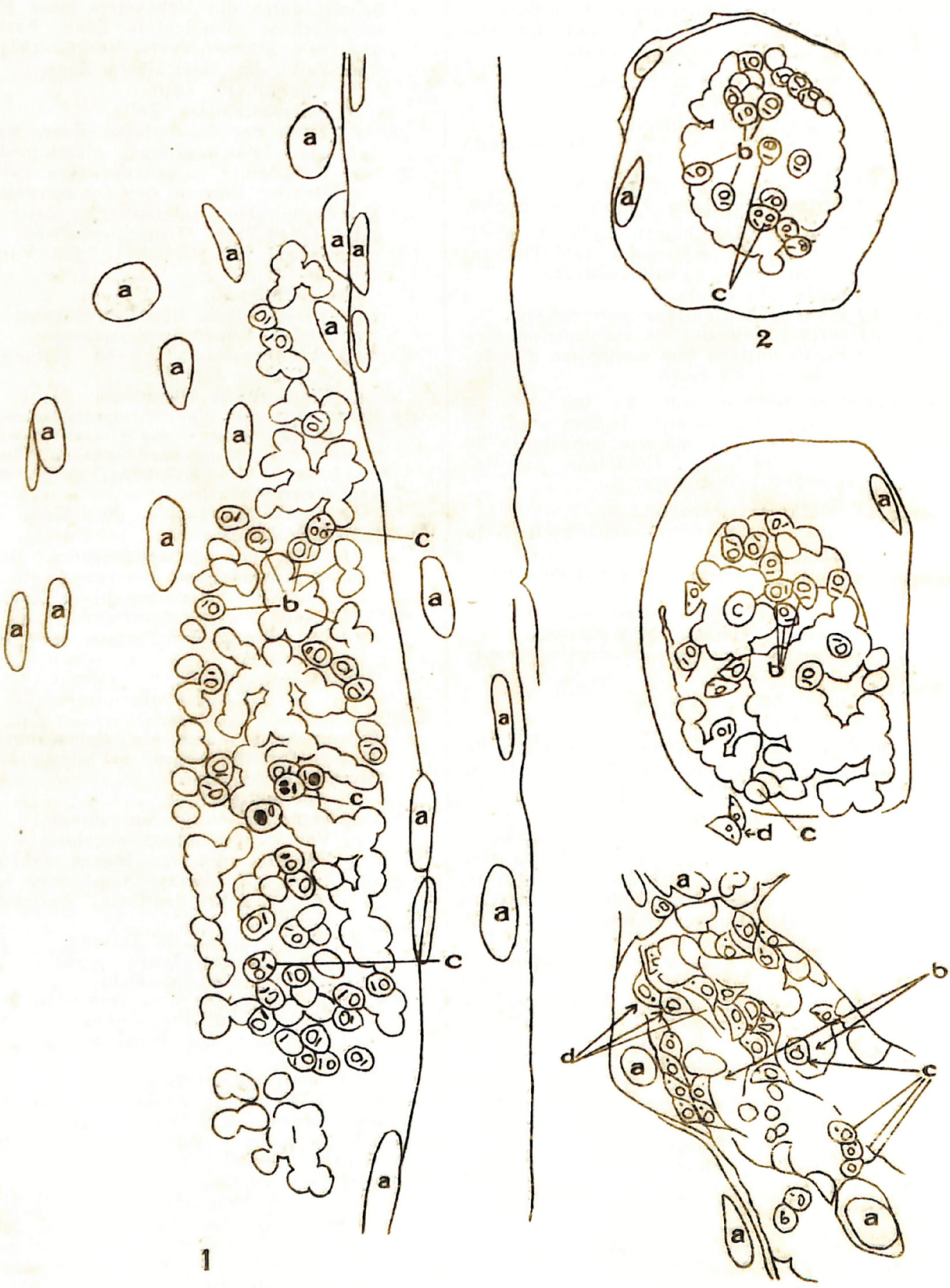

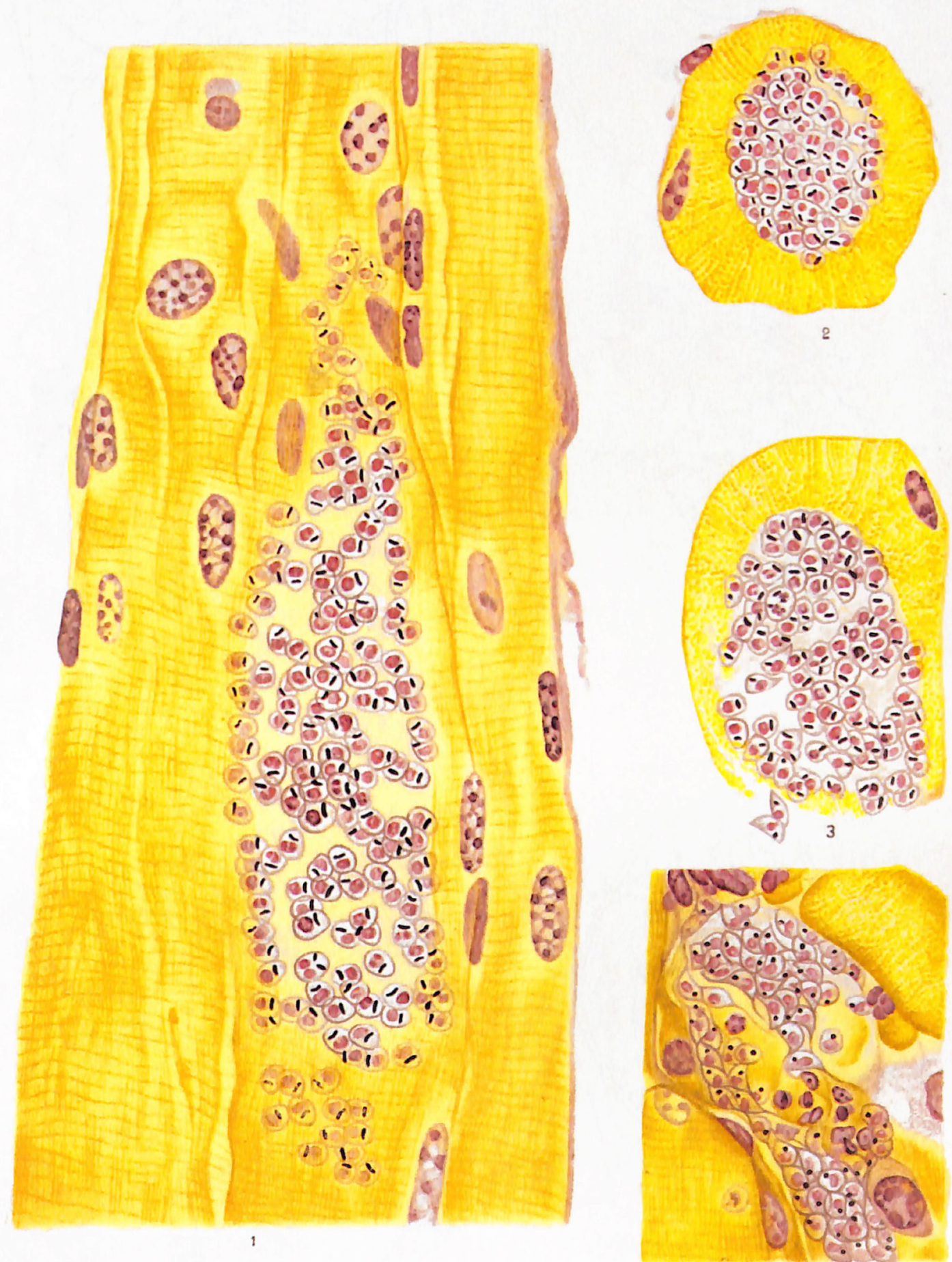

Castrosilva del. 

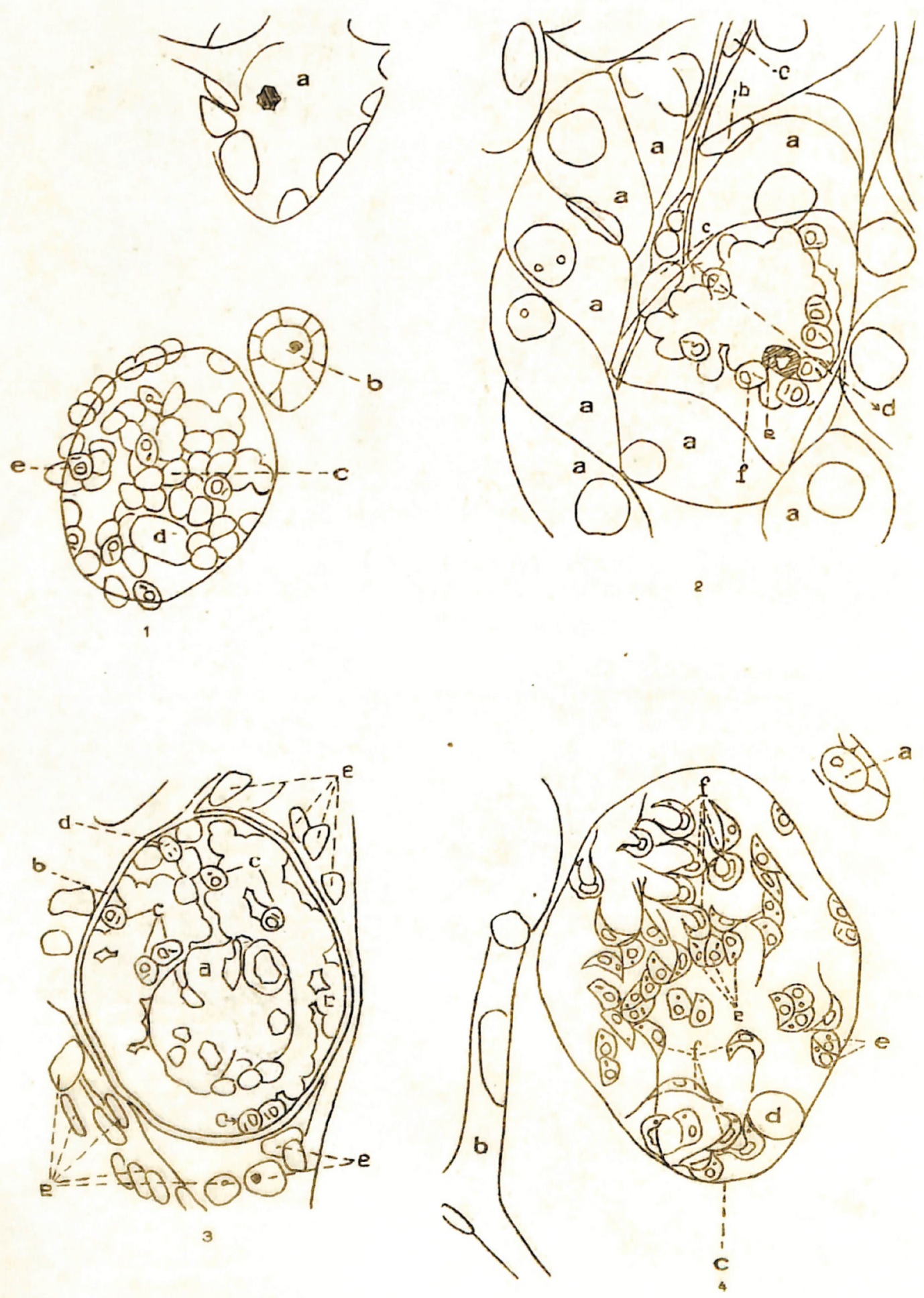
MEMORIAS DO INSTITUTO OSWALDO CRUZ Tомо III - 1911

ESTAMPA 15
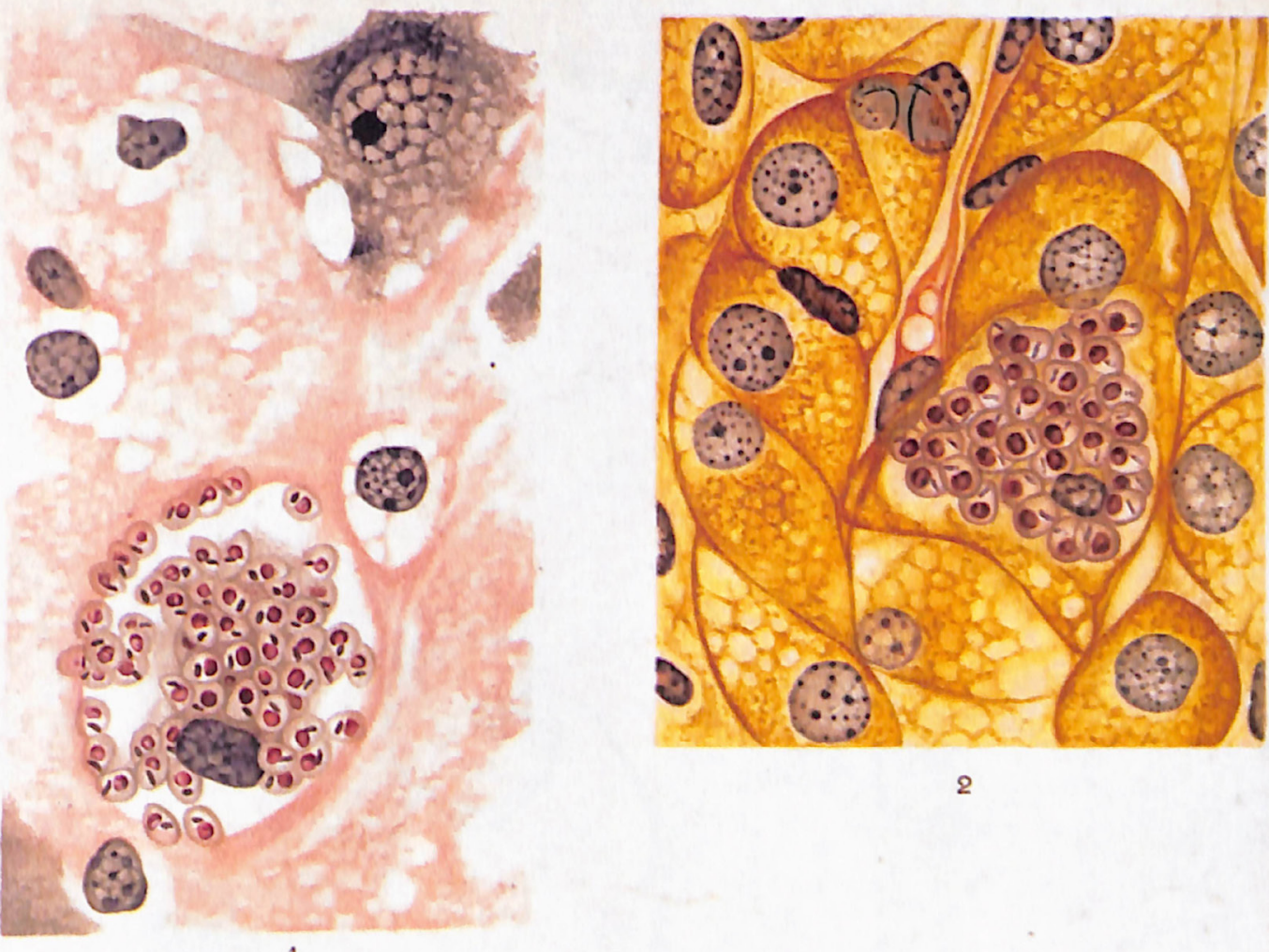

2
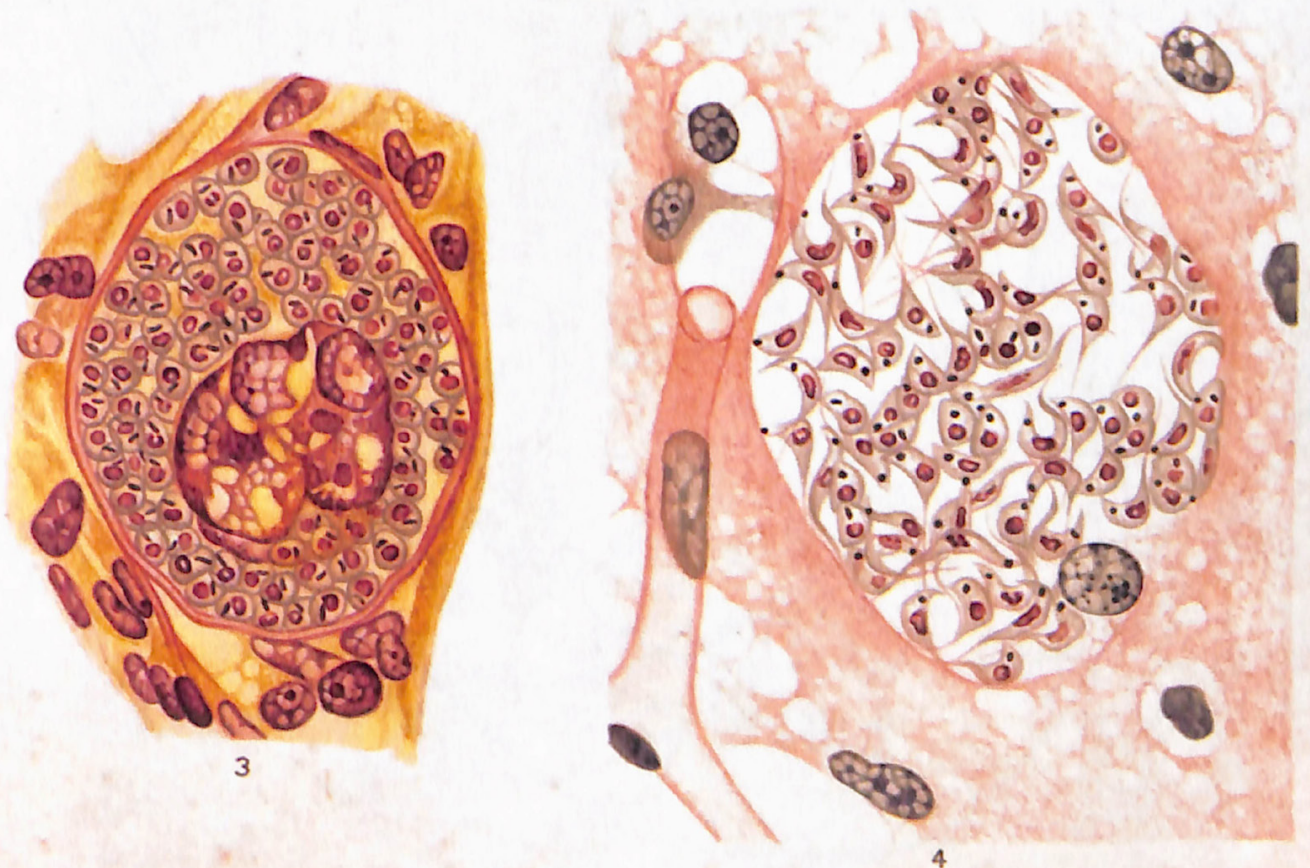

Castrosilva.del. 
MEMORIAS DO INSTITUTO OSWALOO CFUZ

- TOMO III- I9II -

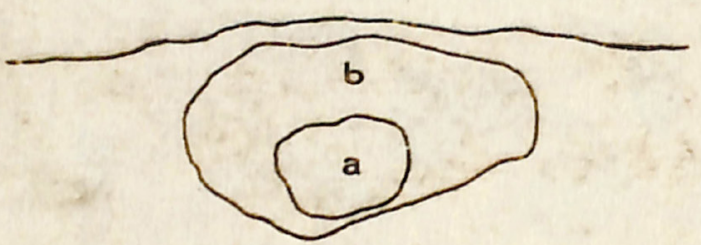

2
ESTAMPA 16

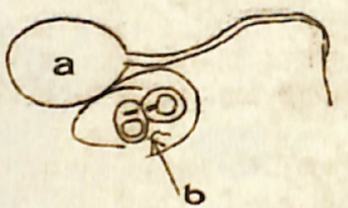

$\sqrt{(b)})^{(0)}-d$

(0i)

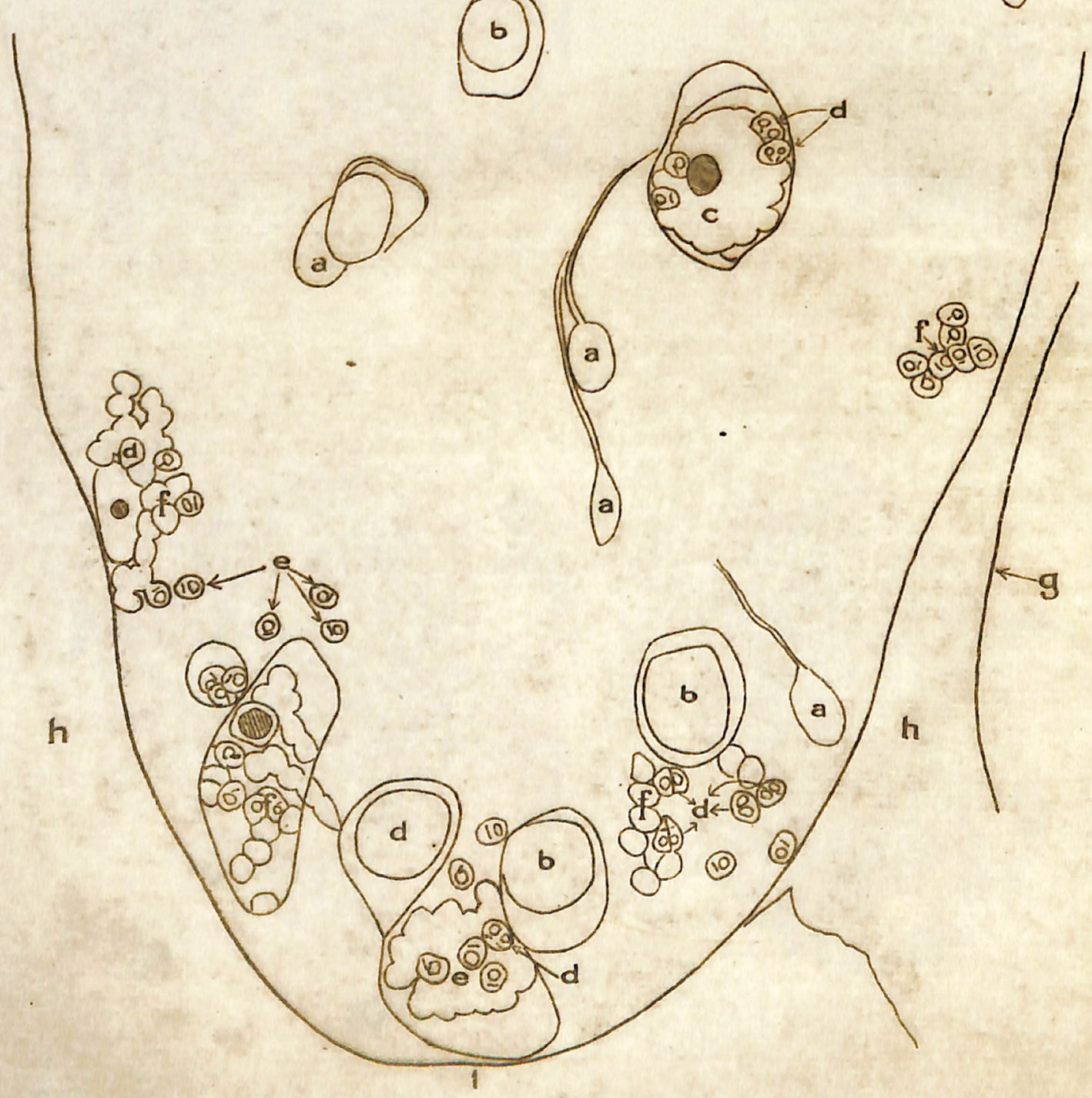



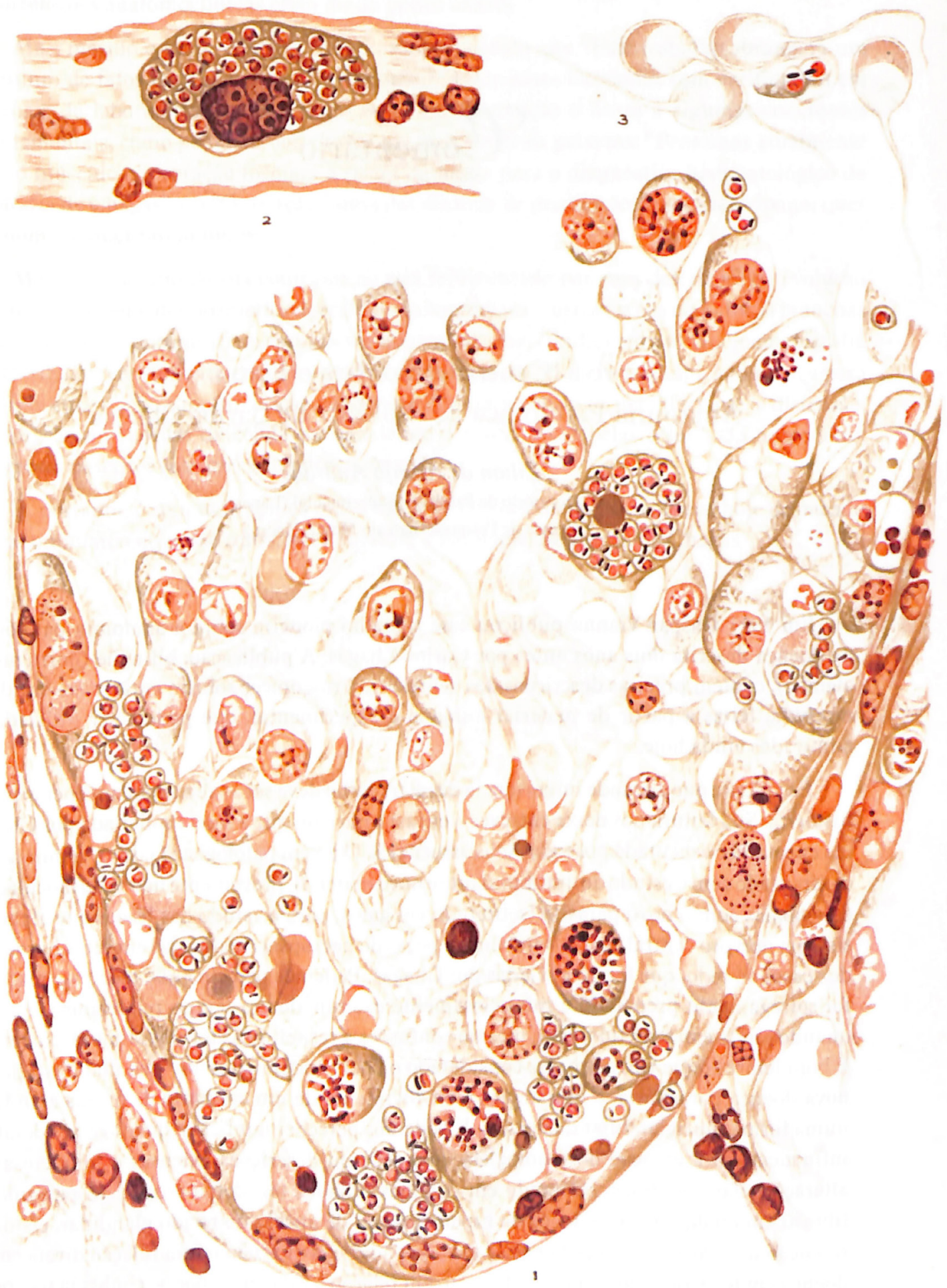


\title{
Sobre a 'Contribuição para o Estudo da Anatomia Patológica da Moléstia de Carlos Chagas’
}

\author{
Zilton de Araújo Andrade \\ Laboratório de Patologia Experimental (Lapex) \\ Centro de Pesquisa Gonçalo Moniz/Fiocruz
}

Em 1911 Gaspar Vianna publicou esse trabalho pioneiro sobre a anatomia patológica da doença descrita dois anos antes por Carlos Chagas. A publicação, bilíngüe (português e alemão), contém precisas descrições dos achados microscópicos sobre a então nova entidade mórbida, feitas a partir de material humano e experimental, que podem ser utilizadas e admiradas ainda hoje.

É evidente que a grande importância desse trabalho deve ser avaliada em uma perspectiva histórica. Sua leitura nos deixa entrever o entusiasmo com que a tarefa solicitada por Chagas era encarada e executada por todos seus associados. O jovem patologista Gaspar Vianna se viu confrontado com o estudo de um abundante e novo material, proveniente não só de inoculações em cobaias com o novo parasito (sobretudo em gatos, para o estudo das lesões que afetam o sistema nervoso central), como também de peças de necropsias realizadas em seres humanos, dez casos ao todo, que foram enviadas por Chagas. Podemos perceber que todo esse material foi sofregamente preparado e minuciosamente examinado em tempo relativamente curto, quando ainda existiam dúvidas e mesmo confusões a respeito das formas clínicas existentes. É bom lembrar que Chagas havia considerado o bócio endêmico como uma manifestação da nova doença parasitária, e investigava o envolvimento de um conjunto de outras glândulas numa forma pluriglandular da doença. E podemos perceber também o quanto esses detalhes influenciaram a atenção do patologista, que dedicou descrições extensas e minuciosas às alterações das glândulas, relatando em detalhes achados tais como áreas de espessamento fibroso em qualquer órgão, focos de hiperplasia ou de atrofia do tecido glandular, cistos de retenção no ovário, esteatose hepática etc., que hoje sabemos não terem relação direta com a doença em foco, mas cujo significado exato em relação a esta ainda não se conhecia na época. Por outro lado, a noção dominante no momento era de que a nova doença se apresentava como uma infecção generalizada, aguda, com parasitos se disseminando por vários órgãos, embora pudessem aparecer também várias formas crônicas. Além disso, a anatomia 
patológica da época era uma disciplina essencialmente descritiva, e como a documentação iconográfica era difícil e laboriosa, as palavras deveriam fornecer uma descrição minuciosa e exata das alterações vistas nas necropsias ou ao microscópio. Interpretações fisiopatológicas e correlações anatomoclínicas eram ainda pouco usuais.

Mas, mesmo o autor tendo declarado modestamente que "Este trabalho abrangerá um conjunto de fatos histopatológicos já estabelecidos em casos humanos, com verificações em animais de laboratório", o seu arguto senso de observação o levou a algumas conclusões fundamentais, como podemos comprovar nas suas próprias palavras: "Pensamos atualmente que o músculo e o coração formam a pedra de toque para o diagnóstico histopatológico da moléstia de Chagas", ou "O coração é uma das vísceras de predileção do esquizotripano, quer no homem, quer nos animais".

Mas, o ponto alto da sua contribuição está representado por suas descrições da evolução dinâmica dos parasitos no interior das células do hospedeiro, ilustradas nas magníficas pranchas coloridas, que só encontrariam equivalente muitos anos mais tarde, com a microcinematografia de Hertha Meyer. Todos os detalhes, desde a penetração na célula hospedeira, a mudança para a forma amastigota, a multiplicação por divisão binária, a volta à forma infectante, a distensão, perfuração ou ruptura da célula parasitada até a reação focal pelas células do hospedeiro, aparecem descritos com precisão impressionante.

É, portanto, é com toda justiça que o trabalho de Gaspar Vianna aparece hoje destacado como um marco no nosso conhecimento sobre a patologia da doença de Chagas. 